\title{
Analyses of antioxidant status and nucleotide alterations in genes encoding antioxidant enzymes in patients with benign and malignant thyroid disorders
}

\author{
Nur Siti Fatimah Ramli ${ }^{1}$, Sarni Mat Junit ${ }^{1}$, Ng Khoon Leong ${ }^{2}$, Nurhanani Razali ${ }^{1}$, Jaime Jacqueline \\ Jayapalan ${ }^{3}$, Azlina Abdul Aziz ${ }^{\text {Corresp. } 1}$ \\ 1 Department of Molecular Medicine, Faculty of Medicine, University of Malaya, Kuala Lumpur, Malaysia \\ 2 Department of Surgery, Faculty of Medicine, University of Malaya, Kuala Lumpur, Malaysia \\ 3 University of Malaya Centre for Proteomics Research (UMCPR), University of Malaya, Kuala Lumpur, Malaysia \\ Corresponding Author: Azlina Abdul Aziz \\ Email address: azlina_aziz@um.edu.my
}

Background: Synthesis of thyroid hormones and regulation of their metabolism involve free radicals that may affect redox balance in the body. Thyroid disorders causing variations in the levels of thyroid hormones may alter cellular oxidative stress. The aim of this study was to measure the antioxidant activities and biomarkers of oxidative stress in serum and red blood cells (RBC) of patients with benign and malignant thyroid disorders and to investigate if changes in the antioxidant activities in these patients were linked to alterations in genes encoding the antioxidant enzymes.

Methods: Forty one patients with thyroid disorders from University of MalayaMedical Centre were recruited. Theywere categorised into four groups;multinodulargoitre, MNG $(n=18)$, follicular thyroid adenoma, FTA $(n=7)$, papillary thyroid cancer, PTC $(n=10)$, and follicular thyroid cancer, FTC $(n=6)$. Serum and RBC of patients were analysed for antioxidant activities, antioxidant enzymes and biomarkers of oxidative stress. Alterations in genes encoding the antioxidant enzymes were analysed using whole exome sequencing and PCR-DNA sequencing.

Results: Patients with thyroid disorders had significantly higher serum superoxide dismutase (SOD) and catalase (CAT) activities compared to control, but had lower activities in RBC. There were no significant changes in serum glutathione peroxidase (GPx) activity. Meanwhile, GPx activity in RBC was reduced in PTC and FTC, compared to control and the respective benign groups. Antioxidant activities in serum were decreased in the thyroid disorder groups when compared to the control group. The levels of malondialdehyde (MDA) were elevated in the serum of FTA group when compared to controls, while in the RBC, only the MNG and PTC groups showed higher MDA equivalents than control. Serum reactive oxygen species (ROS) levels in PTC group of both serum and RBC were significantly higher than control group. Whole exome sequencing has resulted in identification of 49 single nucleotide polymorphisms (SNPS) in MNG and PTC patients and their genotypic and allelic frequencies were calculated. Analyses of the relationship between serum enzyme activities and the total SNPs identified in both groups revealed no correlation.

Discussion: Different forms of thyroid disorders influence the levels of antioxidant status in the serum and RBC of these patients, implying varying capability of preventing oxidative stress. A more comprehensive study with a larger target population should be done in order to further evaluate the relationships between antioxidant enzymes gene polymorphisms and thyroid disorders, as well as strengthening the minor evidences provided in literatures. 
1 Analyses of antioxidant status and nucleotide alterations in genes encoding antioxidant enzymes

2

3

4

5

6

$7 \quad{ }^{1}$ Department of Molecular Medicine, Faculty of Medicine, University of Malaya, 50603, Kuala

$$
\text { in patients with benign and malignant thyroid disorders }
$$

$$
\text { Nur Siti Fatimah Ramli }{ }^{1} \text {, Sarni Mat Junit }{ }^{1} \text {, Ng Khoon Leong }{ }^{2} \text {, Nurhanani Razali }{ }^{1} \text {, Jaime }
$$$$
\text { Jacqueline Jayapalan }^{3} \text {, Azlina Abdul Aziz }{ }^{*}
$$

6

.

8
${ }^{2}$ Department of Surgery, Faculty of Medicine, University of Malaya, 50603, Kuala Lumpur
Malaysia.

13 University of Malaya Centre for Proteomics Research (UMCPR), University of Malaya, Kuala

2
Lumpur 50603, Malaysia 


\section{Abstract}

Background: Synthesis of thyroid hormones and regulation of their metabolism involve free radicals that may affect redox balance in the body. Thyroid disorders causing variations in the levels of thyroid hormones may alter cellular oxidative stress. The aim of this study was to measure the antioxidant activities and biomarkers of oxidative stress in serum and red blood cells (RBC) of patients with benign and malignant thyroid disorders and to investigate if changes in the antioxidant activities in these patients were linked to alterations in genes encoding the antioxidant enzymes.

Methods: Forty one patients with thyroid disorders from University of Malaya Medical Centre were recruited. They were categorised into four groups; multinodular goitre, MNG (n=18), follicular thyroid adenoma, FTA $(n=7)$, papillary thyroid cancer, PTC $(n=10)$, and follicular thyroid cancer, FTC $(n=6)$. Serum and RBC of patients were analysed for antioxidant activities, antioxidant enzymes and biomarkers of oxidative stress. Alterations in genes encoding the antioxidant enzymes were analysed using whole exome sequencing and PCR-DNA sequencing.

Results: Patients with thyroid disorders had significantly higher serum superoxide dismutase (SOD) and catalase (CAT) activities compared to control, but had lower activities in RBC. There were no significant changes in serum glutathione peroxidase (GPx) activity. Meanwhile, GPx activity in RBC was reduced in PTC and FTC, compared to control and the respective benign groups. Antioxidant activities in serum were decreased in the thyroid disorder groups when compared to the control group. The levels of malondialdehyde (MDA) were elevated in the serum of FTA group when compared to controls, while in the RBC, only the MNG and PTC groups showed higher MDA equivalents than control. Serum reactive oxygen species (ROS) levels in PTC group of both serum and RBC were significantly higher than control group. Whole exome sequencing has resulted in identification of 49 single nucleotide polymorphisms (SNPs) in MNG and PTC patients and their genotypic and allelic frequencies were calculated. Analyses of the relationship between serum enzyme activities and the total SNPs identified in both groups revealed no correlation. 
59

60

61

62

63

64

65

66

67

68

69

70

71

72

73

74

75

76

77

78

79

80

Discussion: Different forms of thyroid disorders influence the levels of antioxidant status in the serum and RBC of these patients, implying varying capability of preventing oxidative stress. A more comprehensive study with a larger target population should be done in order to further evaluate the relationships between antioxidant enzymes gene polymorphisms and thyroid disorders, as well as strengthening the minor evidences provided in literatures.

\section{Introduction}

Thyroid hormones play important roles in the body including regulating metabolic rate and oxidative metabolism as well as stimulating growth and protein synthesis. Thyroid gland dysfunction is known to alter lipid profiles, potentially causing conditions such as hypertension, insulin resistance and oxidative stress. During the production of thyroid hormones, reactive oxygen species (ROS) are generated as part of the process. However, under normal redox balance, the ROS are removed by antioxidant systems in the body, hence limiting oxidative damage. On the other hand, certain conditions such as inflammation of the thyroid gland as well as tumour cell proliferation could alter the balance between ROS and antioxidant levels (Cetin et al. 2015) in favour of the former, subsequently leading to oxidative damage (Erdamar et al. 2010). In particular, the utilisation of $\mathrm{H}_{2} \mathrm{O}_{2}$ for thyroid hormones synthesis causes the thyroid to be easily exposed to oxidative stress in situation where there is disorder in thyroid hormones production (Karbownik-Lewińska \& Kokoszko-Bilska 2012).

Several studies have shown the link between oxidative stress and cancer, including thyroid cancer (Florian et al. 2010; Noda \& Wakasugi 2001; Wang et al. 2011). Although some information is known about the antioxidant status of patients with thyroid disorders (Erdamar et al. 2010; Senthil \& Manoharan 2004; Wang et al. 2011), comparisons between the benign and malignant groups have rarely been performed, especially on two types of benign thyroid disorders which are multinodular goitre (MNG) and follicular thyroid adenoma (FTA). Hence, this study focuses on MNG and FTA as the benign groups, while two of the most common thyroid cancers, papillary (PTC) and follicular (FTC) as the malignant groups. Such comparisons can provide data on the potential associations between oxidative stress and development of malignant form from the benign cases. 
90

91

92

93

94

95

96

97

98

As the metabolic effects of thyroid hormones are linked to oxidative stress, genetic variations in antioxidant enzymes may also have an impact on the endogenous antioxidant defence system (Da Costa et al. 2012; Maier et al. 2007). There is a lack of studies investigating the genetic variations of antioxidant enzymes in relation to thyroid disorder-associated oxidative stress, particularly through single nucleotide polymorphism (SNP) analyses.

Therefore, the aim of this study was to analyse the antioxidant status in patients with thyroid disorders by measuring antioxidant activities and parameters of oxidative stress including antioxidant enzyme activities, lipid peroxidation and levels of ROS. In addition, nucleotide alterations in genes encoding the antioxidant enzymes, SOD, GPx and CAT, were screened in order to assess the underlying genetic cause that may be linked to thyroid disorders. For the screening of gene alterations, whole exome sequencing analysis were performed in both MNG $(n=9)$ and PTC $(n=9)$ groups as they are the most common form of thyroid disorders. To minimise cost, gene alterations detected in the MNG and PTC patients were reanalysed in patients with FTC $(n=5)$; a less common form of thyroid cancer, by PCR-DNA sequencing analysis.

\section{Materials and Methods}

\section{Subjects}

A total of 41 patients with thyroid gland disorders from University of Malaya Medical Centre (UMMC), Kuala Lumpur were involved in this study. Consents were obtained from all the patients before proceeding with the collection of samples. Ethical clearance for this study was obtained from the UMMC medical ethics committee (reference number: 925.8). The patients were categorised into four groups according to their diagnosis of thyroid gland disorders; multinodular goitre (MNG), follicular thyroid adenoma (FTA), papillary thyroid cancer (PTC), and follicular thyroid cancer (FTC). Their blood samples were taken prior to surgery, for antioxidant analyses and thyroid function tests. In addition, a total of 14 healthy subjects served as control group. Blood samples of the patients and control group were sent to Clinical Diagnostic Laboratory (CDL) of UMMC for the analyses of TFT using ADVIA Centaur CP Immunoassay System (TSH normal reference range: 0.55-4.78 mU/L; fT4 normal reference range: $11.5-22.7 \mathrm{pmol} / \mathrm{L})$ (Table 1). 
122 Meanwhile tissue samples of thyroid glands taken from patients with thyroid disorders were used 123 for analyses of genes encoding the antioxidant enzymes. For the whole exome sequencing 124 (WES) analysis, selected patients from the MNG $(n=9)$ and PTC $(n=9)$ groups were included. 125 For comparison, genes alterations detected in the MNG and PTC patients were also analysed in 126 the FTC patients, using PCR-DNA sequencing. Tissue samples were extracted from the nodule 127 and their clinical diagnoses were confirmed by histopathological examination via H\&E stain. 128 The tissue samples were kept fresh-frozen prior to DNA extraction.

129

130

131

132

133

134

135

136

137

138

139

140

141

142

143

144

145

146

147

148

149

150

151

\section{Blood samples}

Blood (3 mL) was drawn by venepuncture from the subjects. Serum was collected into BD Vacutainer ${ }^{\circledR}$ SST tube and was centrifuged at $2236 \mathrm{x}$ g for 15 minutes at $4^{\circ} \mathrm{C}$. Whole blood was collected into BD Vacutainer ${ }^{\circledR}$ K2EDTA tube and centrifuged at $2236 \mathrm{xg}$ for 15 minutes at $4^{\circ} \mathrm{C}$ to separate plasma and red blood cells (RBC). Plasma was isolated and the RBC was washed with phosphate buffered saline (PBS) three times, followed by centrifugation at $1000 \mathrm{x} g$ for 5 minutes at $4^{\circ} \mathrm{C}$. Double distilled water was added into the tube, and the $\mathrm{RBC}$ was allowed to lyse for 2 hours at $4^{\circ} \mathrm{C}$. After the incubation, RBC was centrifuged at $2000 \mathrm{x} \mathrm{g}$ for 15 minutes at $4^{\circ} \mathrm{C}$. The supernatant, containing lysed RBC, and the serum samples were stored at $-80^{\circ} \mathrm{C}$ until further analysis.

\section{Superoxide dismutase (SOD)}

SOD enzyme activity was measured using commercially available Superoxide Dismutase (SOD) Assay Kit (Cayman, USA) according to the manufacturer's protocol. Serum and RBC samples were diluted to 1:5 and 1:100 with sample buffer respectively. The measurement was based on the activity of SOD in the sample to cause dismutation of the superoxide radicals generated by xanthine oxidase and hypoxanthine. The absorbance was read at $450 \mathrm{~nm}$. One unit of SOD is defined as the amount of enzyme needed to exhibit 50\% dismutation of the superoxide radicals. The analyses were performed in triplicate.

\section{Catalase (CAT)}


152 CAT enzyme activity was measured using commercially available Catalase (CAT) Assay Kit

153 (Cayman, USA) according to the manufacturer's protocol. The assay utilised the peroxidatic

154 function of the enzyme. Formaldehyde served as the standard, and samples were diluted with 155 sample buffer in a ratio of 1:5 for serum, and 1:1000 for RBC prior to the assay. The reactions 156 were initiated with the addition of $\mathrm{H}_{2} \mathrm{O}_{2}$. The assay is based on the reactions of CAT with 157 methanol in the presence of $\mathrm{H}_{2} \mathrm{O}_{2}$. The absorbance was read at $550 \mathrm{~nm}$ using a plate reader. CAT 158 activity was expressed as unit/mL whereby one unit is defined as the amount of enzyme that will 159 cause the formation of $1.0 \mathrm{nmol}$ of formaldehyde per minute at $25^{\circ} \mathrm{C}$. The assays were done in 160 triplicate.

161

\section{Glutathione peroxidase (GPx)}

GPx enzyme activity was measured using commercially available Glutathione Peroxidase (GPx)

164

165

166

167

168

169

170

171

172

173

174

175

176

177

178

179

180

181 Assay Kit (Cayman, USA), according to the manufacturer's protocol. Serum and RBC samples were diluted into 1:10 ratio with sample buffer. GPx activity was measured indirectly by a coupled reaction with glutathione reductase, and the reactions were initiated by the addition of cumene hydroperoxide. The absorbance was read every minute at $340 \mathrm{~nm}$ for 5 minutes using a plate reader to obtain five time points. GPx activity was expressed as unit/mL whereby one unit is defined as the amount of enzyme that will cause the oxidation of $1.0 \mathrm{nmol}$ of NADPH to $\mathrm{NADP}^{+}$per minute at $25^{\circ} \mathrm{C}$. All analyses were performed in triplicate.

\section{ABTS radical scavenging activity}

The 2,2'-azino-bis(3-ethylbenzothiazoline-6-sulphonic acid) (ABTS) radical scavenging activity in the blood samples was measured based on the method of Luis, et al (2008) with slight modification. ABTS $(7 \mathrm{mM})$ and potassium persulfate $(2.45 \mathrm{mM})$ were mixed together to generate $\mathrm{ABTS}^{++}$radical cation by incubating the solution in the dark at room temperature for 16 hours. The solution was then diluted with methanol to obtain an absorbance of $0.70 \pm 0.02$ at 415 $\mathrm{nm}$. Four microliters of samples (serum or RBC) were added to $400 \mu \mathrm{L}$ of ABTS reagent and the mixture was incubated in the dark for 10 minutes. After incubation, the sample was centrifuged at $1643 \mathrm{x} g$ for 1 minute, and the absorbance of the supernatant was read at $415 \mathrm{~nm}$. Trolox was used as standard and was similarly analysed as above. Trolox standard curve was plotted with a 
182 concentration range of $0,0.5,1,1.5$, and $2 \mathrm{mM}$. The final results were expressed as Trolox 183 equivalent antioxidant capacity (TEAC).

184

185

186

187

188

189

190

191

192

193

194

195

196

197

198

199

200

201

202

203

204

205

206

207

208

209

210

211

212

\section{ROS scavenging assay}

Dichlorofluorescein diacetate (DCF-DA) was used as the fluorescence-based probe for the detection of ROS in the blood samples. In the assay, $5 \mu 1$ of sample and $100 \mu 1$ of DCF-DA reagent $(20 \mu \mathrm{M})$ were added into a black 96-well plate and was incubated for 30 minutes at room temperature. Fluorescence reading was taken with the excitation and emission wavelengths set at $485 \mathrm{~nm}$ and $530 \mathrm{~nm}$, respectively (Bioplex 200 Systems) (Bio-Rad, USA). All reactions were done in triplicate. Results were expressed as relative fluorescence unit (RFU).

\section{Lipid peroxidation}

Thiobarbituric acid reactive substances (TBARS) assay was used in estimating lipid peroxidation in the blood samples. Malondialdehyde (MDA) as the by-product of lipid peroxidation, reacted with thiobarbituric acid (TBA) to form TBARS. TBARS reagent was prepared by mixing $0.3 \mathrm{~g}$ of TBA, $12 \mathrm{~g}$ of trichloroacetic acid (TCA) and $1.04 \mathrm{~mL}$ of $70 \%$ perchloric acid $\left(\mathrm{HClO}_{4}\right)$ in 80 $\mathrm{mL}$ of double-distilled water. Sample $(50 \mu \mathrm{L})$ was mixed with $250 \mu \mathrm{L}$ of TBARS reagent and boiled at $90^{\circ} \mathrm{C}$ for 20 minutes. After cooling on ice, the mixture was centrifuged at $309 \times \mathrm{g}$ for 10 minutes at $25^{\circ} \mathrm{C}$. Absorbance of the supernatant was read at $532 \mathrm{~nm}$ (Bio-Rad Model 680 microplate reader, California, USA). A standard curve was constructed using 1,1,3,3tetraethoxypropane, TEP $(0-100 \mathrm{ng} / \mu \mathrm{L})$. Protein content of the sample was measured using Bradford protein assay, with bovine serum albumin (BSA) as the standard. The levels of lipid peroxidation were expressed as nmol MDA equivalents/mg of protein. All analyses were performed in triplicate.

\section{Molecular analysis}

DNA extraction and whole exome sequencing

DNA samples of the patients; MNG $(n=9)$ and PTC $(n=9)$, were sent to BGI Tech Solutions, Shenzhen, China for WES analysis. The protocols were based on the Agilent SureSelect XT Target Enrichment System for Illumina Paired-End Sequencing which involved the following 
213 steps; library preparation, hybridisation and capture, and sequencing. The raw image files

214 obtained from the sequencing were processed using the Illumina Software1.7 via base-calling,

215 and the raw data was saved in the FASTQ format. The quality control (QC) step was performed

216 using FastQC (www.bioinformatics.babraham.ac.uk). Data filtering was applied to the FASTQ

217 data and the sequencing reads were aligned to the Reference Genome of human genome build37

218 (hg19) using BWA software (bio-bwa.sourceforge.net). The SOAPsnp software was used for

219 SNP calling (soap.genomics.org.cn) and following identification of SNPs, an in-house AnnoDB

220 software (AnnotationDB) was used for RefGene annotation.

221

222 SNP genotyping of FTC patients

223 TaqMan SNP Genotyping Assays (Applied Biosystems, USA) were used to amplify specific

224 SNP alleles in purified DNA samples of FTC $(n=5)$ patients using real-time polymerase chain 225 reaction (qRT-PCR). The list of genes with their respective SNP primers used for the qRT-PCR 226 are listed in Table 2. qRT-PCR amplification was performed in $0.2 \mathrm{~mL}$ MicroAmp® Optical 8227 tube strips in a final volume of $10 \mu \mathrm{L}$ that consisted of $5 \mu \mathrm{L}$ of $2 \mathrm{X}$ TaqMan® Genotyping Master 228 Mix, $0.5 \mu \mathrm{L}$ of TaqMan® DME Genotyping Assay Mix, and genomic DNA diluted in distilled 229 water (10 ng). qRT-PCR was performed using the following PCR parameters; 10 minutes of 230 initiation steps at $95{ }^{\circ} \mathrm{C}$, followed by 50 cycles of denaturation at $92{ }^{\circ} \mathrm{C}$ for 15 seconds, and 231 annealing steps for 90 seconds.

232

233 Statistical analyses

234 All data for antioxidant analyses were expressed as mean \pm standard error of the mean (SEM), 235 unless otherwise stated. The Statistical Package for Social Sciences (SPSS) version 24.0 (IBM, 236 New York, USA) was used to perform the following statistical analyses. One-way analysis of 237 variance (ANOVA) was used to compare the mean differences of serum and RBC antioxidant 238 analyses between the groups of subjects for all normally distributed dataset whilst the non239 parametric Kruskal-Wallis test was used, if otherwise. The Tukey post-hoc test was used for 240 multiple comparisons of specific sample pairs when equal variances were assumed whilst 241 Dunnett's T3 post-hoc test was used when unequal variances were assumed. Levene's test of 242 homogeneity of variances was used to verify the assumption. Spearman's correlation coefficient 
243 test was used to compare the association between SNPs and antioxidant enzyme activities among

244 MNG and PTC groups of subjects.

245

246 Hardy-Weinberg exact test was used to test the genetic equilibrium of the SNPs using Genepop

247 (version 4.2) population genetics software package (Raymond \& Rousset 1995; Rousset 2008).

248 The distribution of alleles and genotypes of SNPs between MNG, PTC and FTC were analysed

249 using Fisher's exact test.

250

251 P-values less than 0.05 were considered significant.

252

\section{Results}

254 Table 1 shows the demographic and clinical characteristics of patients, together with their 255 thyroid function tests. The patients' age ranged from 14-80 years old while the controls ranged 256 from 29-66 years old. Only two patients were diagnosed with thyroiditis, implying that 257 thyroiditis is not common among the recruited patients. There was no significant difference 258 between the TSH concentration and fT4 values between the control group and the thyroid 259 disorder groups $(\mathrm{p}>0.05)$.

260

261

\section{Antioxidant response and oxidative stress in serum}

262

263

Figure 1 (a-c) shows the antioxidant enzyme activities in serum of control and patients. Patients 264 from the MNG and PTC groups had significantly higher levels of SOD activities (more than 4folds) compared to control (Figure 1 a). Out of the four thyroid disorder groups, only MNG 266 showed higher CAT activities than control (Figure 1 b). Meanwhile, there were no significant 267 differences in GPx activities between control subjects and the thyroid disorder groups (Figure 1 $268 \mathrm{c})$.

Analysis of ABTS radical scavenging activity shows the thyroid disorder groups to have significantly lower antioxidant activities than the control group $(\mathrm{p}<0.05)$ (Figure $1 \mathrm{~d})$. Amongst

272 the four diseased groups, PTC showed the lowest ABTS radical scavenging activity which was 273 significantly lower than its benign form, MNG. Lipid peroxidation was estimated by measuring 
274 levels of malondialdehyde (MDA), a by-product of lipid peroxidation. Levels of MDA

275 equivalents were found to be significantly increased in the FTA group, compared to control

276 while there was not significant difference in the remaining groups (Figure 1 e). Another

277 parameter for oxidative stress that was measured was levels of ROS (Figure $1 \mathrm{f}$ ). ROS level was

278 significantly higher in the PTC group, compared to control while there were no changes in the

279 remaining groups.

280

281

Antioxidant response and oxidative stress in $\mathrm{RBC}$

282

283

284

Figure 2 (a-c) shows the antioxidant enzyme activities in RBC of control and patients. Patients with MNG and FTC had significantly lower SOD activities than control (Figure 2 a). Amongst the four thyroid disorder groups, the FTA group showed lower CAT activities than control (Figure 2 b). GPx activities of the malignant groups (PTC and FTC) were significantly lower than the benign (MNG and FTA) and control groups $(\mathrm{p}<0.05)$. On the contrary, there were no significant changes in the MNG and FTA groups when compared to control ( $p>0.05)$ (Figure 2 c).

Analysis of ABTS radical scavenging activities indicated no significant changes among the thyroid disorder groups with that of control (Figure $2 \mathrm{~d}$ ). However, levels of MDA equivalents in MNG and PTC groups were significantly higher than the control group (Figure 2 e) while only the PTC group showed significantly higher level of ROS compared to control (Figure 2 f).

\section{Single nucleotide polymorphisms (SNPs) in patients} gene, and 10 SNPs in CAT gene (Table 3). Out of the total 49 SNPs identified from the sequencing, eight SNPs were observed to be commonly present in both groups of thyroid disorders and in five of the FTC patients (Table 4). Thus, Venn diagrams (Figure 3) were constructed to show the distribution of these SNPs in all the three groups; MNG, PTC and FTC. These diagrams provide information on patients sharing similar polymorphisms among the three types of thyroid disorders groups. The most common SNP for SOD gene is rs752779, detected in all MNG patients $(\mathrm{n}=9), 8$ PTC patients and in all FTC patients $(\mathrm{n}=5)$. Meanwhile rs2536512 304 was detected in 6 PTC patients and only in 3 of MNG and FTC patients. For the GPX gene, four 
305

306

307

308

309

310

311

312

313

314

315

316

317

318

319

320

321

322

323

324

325

326

327

328

329

330

\section{1}

332

333

334

335

SNPs are found to be common; rs1970951, rs381852, rs3763011, and rs8177447. Eight MNG and all PTC patients appeared to have rs1970951 and rs381852, whereas the former and the latter SNPs was detected in 4 and 3 of the FTC patients, respectively. Four FTC and seven patients from each of the MNG and PTC groups have rs3763011. The same FTC and MNG patients as well as all PTC patients have rs8177447. The CAT SNPs; rs769217 and rs769218 were shared by the same patients of MNG $(n=4)$ and PTC $(n=7)$. Meanwhile all FTC patients $(n=5)$ have rs769217, and only 4 FTC patients have rs769218 (Figure 3).

\section{Analysis on genotypic and allelic frequencies}

Genotypic and allelic frequencies in MNG, PTC and FTC patients of the eight SNPs are summarised in Table 4. The Hardy-Weinberg (HW) Exact test showed that the genotype and allele frequencies in all SNPs conformed to HW equilibrium $(\mathrm{p}>0.05)$. The allelic frequency distribution of the eight SNPs $(\mathrm{HW}-\mathrm{p}>0.05)$ in our studied populations was then compared with the healthy subjects of South Asian (SAS) and East Asian (EAS) countries, taken from the database of 1000 Genomes Project Phase 3 allele frequencies (Yates et al. 2016). The populations were categorised as SAS, EAS, MNG, PTC and FTC, and the data are presented in Figure 4 according to their allele frequencies.

Significant differences were detected in the genotype frequencies for two SNPs; rs752779 $(\mathrm{p}=0.03)$ and rs1970951 ( $\mathrm{p}=0.05)$ among the MNG, PTC, and FTC groups (Table 4). For the rs752779, the majority of patients with PTC have GA genotype (78\%) whilst patients with FTC have GG genotype (80\%). Meanwhile, for the rs 1970951, the majority of patients with MNG and PTC have TT genotype (67\% and 78\% respectively) whilst patients with FTC have TC genotype $(80 \%)$. A significant difference in frequency was also observed for the $\mathrm{T} / \mathrm{C}$ allele for the rs1970951 SNP but not for the G/A allele in the rs752779 SNP. All of the other SNPs did not show significant differences in both genotypic and allelic frequencies.

\section{Relationship between serum enzyme activities and total SNPs identified}

The overall results of the total 49 SNPs for the antioxidant enzymes were compared with the respective antioxidant enzyme activities to ascertain if any correlation exists between these two factors, in MNG and PTC patients. The analysis did not demonstrate any correlation between total SNPs and the corresponding antioxidant enzyme activities in the two groups (Figure 5). 


\section{Discussion}

338 Thyroid disorders are more common among females with an estimated incidence of $2 \%$, whereas 339 it is only $0.2 \%$ in males. In fact, being female constitute one of the risk factors for thyroid 340 disorders (Eugène et al. 2005; James \& Kumar 2012). The incidence of thyroid disorders was 341 also reported to increase with age (Sapini et al. 2009). Our study also showed a higher proportion 342 of female patients compared to males.

344 Several studies have been conducted on the effects of thyroid hormones on antioxidant status and oxidative stress (Babu et al. 2011; Cano-Europa et al. 2012; Mancini et al. 2013). Although a majority of studies have reported increased oxidative stress being positively correlated with thyroid disorders, some have also reported the opposite or no changes (Venditti et al. 1997; Villanueva et al. 2013). Studies investigating antioxidant status in thyroid diseases may not include all the crucial parameters to ascertain the relationship between thyroid diseases and antioxidants. Most of the previous studies regarding antioxidant status in thyroid diseases were performed either by evaluating antioxidants as a whole (Sivakanesan et al. 2014; Wang et al. 2011), or by measuring each antioxidants separately (Cetin et al. 2015; Erdamar et al. 2010; Senthil \& Manoharan 2004). In order to overcome this limitation, in this study, we performed analyses to determine both the antioxidant levels as well as parameters of oxidative stress in patients with thyroid disorders to provide an overall picture with regards to the status of antioxidants and oxidative damage.

357

We also compared these indicators between the benign and malignant forms of thyroid disorders to ascertain their potential influence in the development of cancers from the benign forms. Furthermore, we have also analysed the RBC to ascertain the effects of the thyroid disorders on the antioxidant status of RBC. Previous reports have also used thyroid tissues, however, due to difficulty in obtaining thyroid tissue samples, comparisons were made between our results and clinical application of serum in thyroid disorders. 
366

367

368

369

370

371

372

373

374

375

376

377

378

379

380

381

382

383

384

385

386

387

388

389

390

391

392

393

394

395

396

ABTS assay measures the overall antioxidant capacity in the samples. The assay relies on the ability of antioxidants in the serum sample to scavenge ABTS radicals and inhibit oxidation in comparison to Trolox as the standard (Magalhães et al. 2008). Serum may contain some low molecular weight compounds with antioxidant activities such as Vitamin C, Vitamin E and uric acid. Results from both serum and RBC samples in this study generally indicated patients with thyroid diseases tend to have lower antioxidant activities in the serum but no changes in RBC, compared to healthy subjects. A study by Wang et al (2011) that measured antioxidant status of thyroid cancer patients demonstrated similar results as ours. Majority of studies have reported on the lowering of antioxidant activities with hyperthyroidism (Andryskowski \& Owczarek 2007; Asayama et al. 1989; Venditti et al. 2003) although one study has reported no significant changes (Sivakanesan et al. 2014). The lower antioxidant activities were accompanied with increased lipid peroxidation in serum of FTA group and increased ROS in serum of PTC group, implying reduced ability to protect against oxidative stress in these groups. Similar observation was seen for RBCs. PTC has the highest serum ROS concentration among the studied group, possibly due to the substantial reduction in serum antioxidant activities. When comparing between the benign and malignant forms, there was significant reduction in serum antioxidant activities which was accompanied with increased ROS, in PTC group compared to MNG. The same could not be seen between FTA and the malignant form, FTC. The malignancy of the thyroid gland could have led to generation of high amounts of ROS, triggering oxidative stress which in turns lowers the amount of antioxidants.

A study has reported increased MDA levels in thyroid tissues of PTC patients compared to noncancerous tissues (Erdamar et al. 2010). ROS consist of superoxide anion $\left(\mathrm{O}_{2}^{-}\right)$, hydroxyl radicals $\left(\mathrm{OH}^{-}\right)$, nitric oxide $(\mathrm{NO})$, and peroxyl radical $\left(\mathrm{ROO}^{-}\right)$. Their production may be influenced by antioxidant enzymes including SOD, CAT, and GPx. SOD enzyme causes dismutation of superoxide anion radical, leading to production of another radical, hydrogen peroxide $\left(\mathrm{H}_{2} \mathrm{O}_{2}\right)$. CAT and GPx convert $\mathrm{H}_{2} \mathrm{O}_{2}$ into oxygen and $\mathrm{H}_{2} \mathrm{O}$ (MatÉs et al. 1999).

In addition to endogenous antioxidants, the body protects against oxidative damage through antioxidant enzymes. Studies have shown that oxidative stress can affect levels of antioxidant enzymes (Gerenova \& Gadjeva 2005; Sivakanesan et al. 2014; Villanueva et al. 2013), hence 
397 measuring their levels in this study can provide an indication of oxidative stress in the patients.

398 The increase in serum SOD and CAT activities in some of the thyroid disorder groups indicated 399 increased production of superoxide anion and hydrogen peroxide, respectively. Superoxide 400 anions are produced as by-products of the mitochondrial oxidation system. As thyroid hormones 401 also function to regulate the mitochondrial oxidation system, disorders of the thyroid gland may 402 have altered oxidation, leading to increased production of superoxide anion. Similarly, reaction 403 of SOD in removing superoxide anions leads to the production of $\mathrm{H}_{2} \mathrm{O}_{2}$ and this explains the 404 increased CAT activities. The increased SOD and CAT activities could also be due to up405 regulation in the synthesis of these enzymes as a result of the thyroid disorders, as protective 406 response against oxidative stress. However, despite the increased SOD and CAT activities, MDA 407 and ROS levels were still elevated in some groups. This indicates the inability of the cells to 408 completely scavenge the radicals and implies that the rate of clearance of the ROS by these two 409 enzymes is slower than their production. Hyperthyroid rats were reported to have significantly 410 higher lipid peroxidation, SOD, CAT and GPx in liver, together with lower serum antioxidant 411 status (Messarah et al. 2010). It was recently reported that changes in lipid peroxidation and 412 SOD between normal and PTC thyroid tissues can be used as possible markers to differentiate 413 between malignant and non-malignant thyroid tumours (Stanley et al. 2016).

Prolonged excessive production and inadequate removal of ROS can create an oxidative stress environment, leading to DNA damage which can contribute to the pathogenesis of the malignant state. It was recently reported that PRDX1 and PRDX6 expressions were significantly reduced in all PTCs compared to normal tissues, via V600E mutation in the BRAF gene (Nicolussi et al. 2014). PRDXs play several roles in the body including catalysing the reduction of $\mathrm{H}_{2} \mathrm{O}_{2}$. In a recent case report of a patient with concurrent benign thyroid cyst and PTC, based on whole interfere with the MAPK and STAT3 pathways, causing malignant transformation of the benign thyroid nodule (Lee et al. 2016).

Sadani et al (1996) reported increased MDA levels and SOD activities in thyroid tissues of FTA, 426 FTC and PTC patients but no changes in the MNG group. Some of these observations are 427 similar to what we observed in serum of the patients, implying that the changes seen in the serum 
428 could be the result of damage to the thyroid tissues. Also, higher oxidative stress in the serum is

429 indicative of tissue damage due to oxidation, potentially damage from the thyroid tissues

430 themselves. Indeed, studies have reported reduced antioxidant activities and increased ROS

431 production in thyroid glands of patients with thyroid disorders (Sarkar et al. 2006; Venditti et al.

432 2003; Villanueva et al. 2013).

433

434 Results for antioxidant activities, lipid peroxidation and ROS levels obtained in the RBC were 435 similar to serum, in some instances, while for others, were different. SOD activity of RBC was 436 lower than control. One interesting observation from the results of the RBCs is the substantial 437 reduction of GPx activities in both malignant forms of the thyroid disorder, PTC and FTC. 438 Asayama and Kato (1990) and Ferna'ndez and Videla (1989) have reported significant reduction 439 in GPx activity of rats suffering from hyperthyroidism.

440

441 A study reported increased antioxidant enzyme activities in erythrocytes of toxic MNG patients, 442 which is the opposite of what we observed in RBC (Alicigüzel et al. 2001). Another study also 443 reported increased GPx in both hyper- and hypo-thyroid rats but no changes in SOD and CAT

444 (Araujo et al. 2011). It has been reported that erythrocytes of patients/animals with 445 hyperthyroidism showed increased oxygen consumption (Alicigüzel et al. 2001), while Mita et 446 al. (2005) also reported the same observation in peripheral blood mononuclear cells (PMC). This 447 may potentially lead to increased production of ROS, hence altering the redox balance of 448 erythrocytes, in favour of oxidative stress.

Results from our study seem to indicate higher oxidative stress in the serum as opposed to RBC. 451 We speculated that RBC may contain antioxidant response system that is better able to counter 452 the effects of increased ROS production as a result of thyroid disorders. Erythrocytes are 453 exposed to endogenous and exogenous sources of ROS including superoxide anion and $\mathrm{H}_{2} \mathrm{O}_{2}$. 454 However, they are equipped with antioxidant system comprising of non-enzymatic and 455 enzymatic antioxidants, the latter includes CAT, SOD and GPx. The especially low levels of 456 GPx in PTC and FTC groups indicated the inability of erythrocytes to scavenge $\mathrm{H}_{2} \mathrm{O}_{2}$, which is 457 depicted by the increase in ROS and MDA levels. The reduction seen in both the malignant 458 forms implies the possibility of the tumour affecting GPx activities or vice versa. Deficiency of 
459 GPx has been associated with several conditions. Cells/tissues deficient in GPx are more 460 susceptible to oxidative damage, apoptosis, cell injury and cell death (Flentjar et al. 2002; Van 461 Remmen et al. 2004). The substantial reduction in GPx activities in the malignant form of 462 thyroid disorders can be further explored with the aim of potentially using this enzyme as a 463 biomarker.

464

465

466

467

468

469

470

471

472

473

474

475

476

477

478

479

480

481

482

483

484

485

486

487

488

489

As antioxidant enzymes evolve to maintain cellular redox homeostasis, their enzymatic activities may be influenced either directly or indirectly by the respective genes that encode them (Gelain et al. 2009). SOD enzyme is encoded by three different isoforms; SOD1, SOD2 and SOD3. Both SOD1 and SOD3 contain copper and zinc in their catalytic centre but are localised differently; SOD1 is present in the cytosol (CuZn-SOD), while SOD3 is found in the extracellular elements (EC-SOD). SOD2 has manganese as a cofactor and is localised in the mitochondria (Mn-SOD) (Zelko et al. 2002). GPx enzyme is encoded by eight different isoforms (GPX1-GPX8) which are localised mostly in the cytosol, nucleus and extracellular space. CAT enzyme, encoded by CAT gene, is localised in peroxisomes (Margis et al. 2008). Whole exome sequencing analysis resulted in identification of SNPs present in the antioxidant enzyme genes of all 18 patients (MNG and PTC).

Whole exome sequencing analysis resulted in identification of SNPs present in the antioxidant enzyme genes of all 18 patients (MNG and PTC). rs752779 was the most common SNP detected in the patients in this study. This SNP is located at the intergenic region of SOD2 and WTAP genes of chromosome 6q25.3. To date, there is no reported study on the association of this SNP with disease development. rs2536512 is the SNP of SOD3 gene that is located on chromosome 4 15.2. It is a missense variant identified in exon 2 of SOD3 with the base change of $\mathrm{G}$ to $\mathrm{A}$, and amino acid substitution of Alanine to Threonine (A58T). This SNP was reported to be associated with type 2 diabetes and hypertension (Naganuma et al. 2008). A previous study has also reported the association of rs2536512 SNP with significantly greater incidence of breast carcinoma (Hubackova et al. 2012). Although the rs2536512 SNP is non-functional, it was hypothesised that this SNP may act as a genetic marker for susceptibility to type 2 diabetes and hypertension (Naganuma et al. 2008; Tamai et al. 2006). 
490 The rs1970951 SNP is a synonymous variant identified in exon 2 of GPX7 gene with a the base 491 change of $\mathrm{T}$ to $\mathrm{C}$, maintaining the amino acid phenylalanine (F79F). There is no known link 492 between this SNP with any diseases. rs381852 is a missense variant identified in exon 3 of GPX8 493 gene with the base change of $A$ to $G$, and amino acid substitution of Lysine to Arginine 494 (K182R). Meanwhile, both rs3763011 and rs8177447 are from GPX3 gene located at intron 1 495 and intron 4, respectively. CAT is the only enzyme without isoforms, and is encoded by the CAT 496 gene. rs769217 is a synonymous variant in exon 9 of CAT gene with base change of $\mathrm{C}$ to $\mathrm{T}$ 497 without the substitution of Aspartic acid, while C6 rs769218 is located at Intron 1. There is also 498 no known link between this SNP with any diseases.

499

500 A Spearman's correlation coefficient was performed to investigate if an association exists 501 between the antioxidant enzyme activities and SNPs in the genes encoding the antioxidant 502 enzymes, in the thyroid disorder patients. Based on results of the SOD enzyme, the malignant 503 group has a lower number of SNPs $(n=49)$ compared to the benign group ( $n=55)$ (Figure 5a). 504 However, for GPX and CAT (Figure 5b-c), both showed a higher number of SNPs for the 505 malignant groups compared to the benign groups. Nevertheless, there was no significant 506 correlation observed. This indicates that the SNPs for SOD, GPx, and CAT do not appear to 507 influence the corresponding enzyme activities. Interestingly, although not significant, there 508 appeared to be a trend of negative association between SNPs of CAT and GPX with the 509 respective antioxidant enzyme activities, for the benign group whilst a positive association was 510 observed for the malignant group. Further studies using larger sample size could validate this 511 observation. A particular SNP may indicate that one form of the gene is common in some people 512 with that particular trait, which means that the incidence of having certain allele frequency may

513 be linked with the history of the trait rather than affecting the body system mechanisms.

514

\section{Conclusion}

516 This study demonstrates that patients with thyroid disorders have lower antioxidant defence 517 system, potentially predisposing them to oxidative stress. Additionally, different forms of 518 thyroid disorders could influence the levels of antioxidant status in the serum and RBC of these 519 patients, implying varying capability of preventing oxidative stress. No significant association 520 was observed between serum enzyme activities and the total number of SNPs identified in this 
521 study. SNP-disease association study however, demonstrated that the genotypic (and allelic)

522 distributions of rs752779 and rs1970951 are markedly different among subjects with malignant

523 thyroid disorders. The lack of association between other SNPs and thyroid disorders need to be

524 validated in a larger sample size using appropriate controls subjects.

525

526

527

528

529

530

531

532

533

534

535

536

537

538

539

540

541

542

543

544

545

546

547

548

549

550

551

552

553

554

555

556

557

558

559

560

561

\section{Acknowledgement}

We would like to thank all the subjects for their participation.

\section{References}

Alicigüzel Y, Özdem SN, Özdem SS, Karayalçin Ü, Siedlak SL, Perry G, and Smith MA. 2001. Erythrocyte, plasma, and serum antioxidant activities in untreated toxic multinodular goiter patients. Free Radical Biology and Medicine 30:665-670.

Andryskowski G, and Owczarek T. 2007. The evaluation of selected oxidative stress parameters in patients with hyperthyroidism. Polskie Archiwum Medycyny Wewnetrznej 117:285.

Araujo A, Seibel F, Oliveira U, Fernandes T, Llesuy S, Kucharski L, and Belló-Klein A. 2011. Thyroid hormone-induced haemoglobin changes and antioxidant enzymes response in erythrocytes. Cell biochemistry and function 29:408-413.

Asayama K, Dobashi K, Hayashibe K, and K. K. 1989. Vitamin E protects against thyroxineinduced acceleration of lipid peroxidation in cardiac and skeletal muscles in rats. Journal of nutritional science and vitaminology 35:407-418.

Babu K, Jayaraaj IA, and Prabhakar J. 2011. International Journal of Biological \& Medical Research. Int J Biol Med Res 2:1122-1126.

Cano-Europa B-VV, Margarita F-C, and Rocio O-B. 2012. The relationship between thyroid states, oxidative stress and cellular damage. Oxidative stress and diseases Rijeka: InTech.

Cetin B, Kosova F, Akinci M, Atalay C, Seki A, Uyar O, and Ari Z. 2015. Peroxidation Products and Antioxidant Enzyme Activities in Multinodular Goiter and Papillary Thyroid Cancer Patients. Clinical \& Experimental Oncology 2014.

Da Costa LA, Badawi A, and El-Sohemy A. 2012. Nutrigenetics and modulation of oxidative stress. Annals of Nutrition and Metabolism 60:27-36.

Erdamar H, Çimen B, Gülcemal H, Saraymen R, Yerer B, and Demirci H. 2010. Increased lipid peroxidation and impaired enzymatic antioxidant defense mechanism in thyroid tissue with multinodular goiter and papillary carcinoma. Clinical biochemistry 43:650-654. 
562

563

564

565

566

567

568

569

570

571

572

573

574

575

576

577

578

579

580

581

582

583

584

585

586

587

588

589

590

591

592

593

594

595

596

597

598

599

600

601

602

603

604

605

606

607

Eugène D, Djemli A, and Van Vliet G. 2005. Sexual dimorphism of thyroid function in newborns with congenital hypothyroidism. The Journal of Clinical Endocrinology \& Metabolism 90:2696-2700.

Flentjar NJ, Crack PJ, Boyd R, Malin M, de Haan JB, Hertzog P, Kola I, and Iannello R. 2002. Mice lacking glutathione peroxidase-1 activity show increased TUNEL staining and an accelerated inflammatory response in brain following a cold-induced injury. Experimental neurology 177:9-20.

Florian S, Krehl S, Loewinger M, Kipp A, Banning A, Esworthy S, Chu F-F, and BrigeliusFlohé R. 2010. Loss of GPx2 increases apoptosis, mitosis, and GPx1 expression in the intestine of mice. Free Radical Biology and Medicine 49:1694-1702.

Gelain DP, Dalmolin RJ, Belau VL, Moreira JC, Klamt F, and Castro MA. 2009. A systematic review of human antioxidant genes. Front Biosci 14:4457-4463.

Gerenova J, and Gadjeva V. 2005. Changes in parameters of oxidative stress in patients with Graves' disease. Trakia journal of sciences 3:32-36.

Hubackova M, Vaclavikova R, Ehrlichova M, Mrhalova M, Kodet R, Kubackova K, Vrána D, Gut I, and Soucek P. 2012. Association of superoxide dismutases and NAD (P) H quinone oxidoreductases with prognosis of patients with breast carcinomas. International Journal of Cancer 130:338-348.

James R, and Kumar V. 2012. Study on the Prevalence of Thyroid Diseases in Ernakulam City and Cherthala Town of Kerala State, India. International Journal of Scientific and Research Publications 2:1-3.

Karbownik-Lewińska M, and Kokoszko-Bilska A. 2012. Oxidative damage to macromolecules in the thyroid-experimental evidence. Thyroid research 5:1.

Lee CC, Abdullah MI, Junit SM, Ng KL, Wong SY, Siti N, Ramli F, and Hashim OH. 2016. Case Report Malignant transformation of benign thyroid nodule is caused by prolonged H. Int J Clin Exp Med 9:18601-18617.

Magalhães LM, Segundo MA, Reis S, and Lima JL. 2008. Methodological aspects about in vitro evaluation of antioxidant properties. Analytica chimica acta 613:1-19.

Maier J, Van Steeg H, Van Oostrom C, Paschke R, Weiss R, and Krohn K. 2007. Iodine deficiency activates antioxidant genes and causes DNA damage in the thyroid gland of rats and mice. Biochimica et Biophysica Acta (BBA)-Molecular Cell Research 1773:990999.

Mancini A, Raimondo S, Di Segni C, Persano M, Gadotti G, Silvestrini A, Festa R, Tiano L, Pontecorvi A, and Meucci E. 2013. Thyroid hormones and antioxidant systems: focus on 
608

609

610

611

612

613

614

615

616

617

618

619

620

621

622

623

624

625

626

627

628

629

630

631

632

633

634

635

636

637

638

639

640

641

642

643

644

645

646

647

648

649

650

651

652

653

oxidative stress in cardiovascular and pulmonary diseases. International journal of molecular sciences 14:23893-23909.

Margis R, Dunand C, Teixeira FK, and Margis-Pinheiro M. 2008. Glutathione peroxidase family-an evolutionary overview. Febs Journal 275:3959-3970.

MatÉs JM, Pérez-Gómez C, and De Castro IN. 1999. Antioxidant enzymes and human diseases. Clinical biochemistry 32:595-603.

Messarah M, Boumendjel A, Chouabia A, Klibet F, Abdennour C, Boulakoud MS, and El Feki A. 2010. Influence of thyroid dysfunction on liver lipid peroxidation and antioxidant status in experimental rats. Experimental and Toxicologic Pathology 62:301-310.

Naganuma T, Nakayama T, Sato N, Fu Z, Soma M, Aoi N, and Usami R. 2008. A haplotypebased case-control study examining human extracellular superoxide dismutase gene and essential hypertension. Hypertension Research 31:1533.

Nicolussi A, D'Inzeo S, Mincione G, Buffone A, Di Marcantonio MC, Cotellese R, Cichella A, Capalbo C, Di Gioia C, and Nardi F. 2014. PRDX1 and PRDX6 are repressed in papillary thyroid carcinomas via BRAF V600E-dependent and-independent mechanisms. International journal of oncology 44:548-556.

Noda N, and Wakasugi H. 2001. Cancer and oxidative stress. Japan Medical Association Journal 44:535-539.

Raymond M, and Rousset F. 1995. GENEPOP (version 1.2): population genetics software for exact tests and ecumenicism. Journal of heredity 86:248-249.

Rousset F. 2008. genepop'007: a complete re-implementation of the genepop software for Windows and Linux. Molecular ecology resources 8:103-106.

Sapini Y, Rokiah P, and Nor Zuraida Z. 2009. Thyroid disorders and psychiatric morbidities. . Malaysian Journal of Psychiatry 18:60-68.

Sarkar M, Varshney R, Chopra M, Sekhri T, Adhikari JS, and Dwarakanath BS. 2006. Flow-cytometric analysis of reactive oxygen species in peripheral blood mononuclear cells of patients with thyroid dysfunction. Cytometry Part B: Clinical Cytometry 70:2023.

Senthil N, and Manoharan S. 2004. Lipid peroxidation and antioxidants status in patients with papillary thyroid carcinoma in India. Asia Pacific journal of clinical nutrition 13:391395.

Sivakanesan R, Wickramarathne A, and Nanayakkara D. 2014. Serum thyroid stimulating hormone and antioxidant status in patients with suspected thyroid dysfunction. MOJ Clin Med Case Rep 1:00004. 
654

655

656

657

658

659

660

661

662

663

664

665

666

667

668

669

670

671

672

673

674

675

676

677

678

679

680

681

682

683

684

685

686

687

688

689

690
Stanley J, Neelamohan R, Suthagar E, Vengatesh G, Jayakumar J, Chandrasekaran M, Banu S, and Aruldhas M. 2016. Lipid peroxidation and antioxidants status in human malignant and non-malignant thyroid tumours. Human \& experimental toxicology 35:585-597.

Tamai M, Furuta H, Kawashima H, Doi A, Hamanishi T, Shimomura H, Sakagashira S, Nishi M, Sasaki H, and Sanke T. 2006. Extracellular superoxide dismutase gene polymorphism is associated with insulin resistance and the susceptibility to type 2 diabetes. Diabetes research and clinical practice 71:140-145.

Van Remmen H, Qi W, Sabia M, Freeman G, Estlack L, Yang H, Guo ZM, Huang T-T, Strong R, and Lee S. 2004. Multiple deficiencies in antioxidant enzymes in mice result in a compound increase in sensitivity to oxidative stress. Free Radical Biology and Medicine $36: 1625-1634$.

Venditti P, Balestrieri M, Di Meo S, and De Leo T. 1997. Effect of thyroid state on lipid peroxidation, antioxidant defences, and susceptibility to oxidative stress in rat tissues. Journal of Endocrinology 155:151-157.

Venditti P, De Rosa R, and Di Meo S. 2003. Effect of thyroid state on susceptibility to oxidants and swelling of mitochondria from rat tissues. Free Radical Biology and Medicine $35: 485-494$.

Villanueva I, Alva-Sanchez C, and Pacheco-Rosado J. 2013. The role of thyroid hormones as inductors of oxidative stress and neurodegeneration. Oxidative medicine and cellular longevity 2013.

Wang D, Feng J-F, Zeng P, Yang Y-H, Luo J, and Yang Y-W. 2011. Total oxidant/antioxidant status in sera of patients with thyroid cancers. Endocrine-related cancer 18:773-782.

Yates A, Akanni W, Amode MR, Barrell D, Billis K, Carvalho-Silva D, Cummins C, Clapham P, Fitzgerald S, and Gil L. 2016. Ensembl 2016. Nucleic acids research 44:D710-D716.

Zelko IN, Mariani TJ, and Folz RJ. 2002. Superoxide dismutase multigene family: a comparison of the CuZn-SOD (SOD1), Mn-SOD (SOD2), and EC-SOD (SOD3) gene structures, evolution, and expression. Free Radical Biology and Medicine 33:337-349. 


\section{Figure 1}

\section{Antioxidant analysis in serum samples of thyroid patients.}

\# indicates significant difference $(p<0.001)$ between the diseased groups of benign and malignant thyroid disorders (MNG vs PTC, FTA vs FTC).

* indicates significant difference $(p<0.05$ and $>0.01)$ between control and the diseased groups.

** indicates significant difference $(p<0.01$ and $>0.001)$ between control and the diseased groups.

*** indicates significant difference $(p<0.001)$ between control and the diseased groups.

*Note: Auto Gamma Correction was used for the image. This only affects the reviewing manuscript. See original source image if needed for review. 


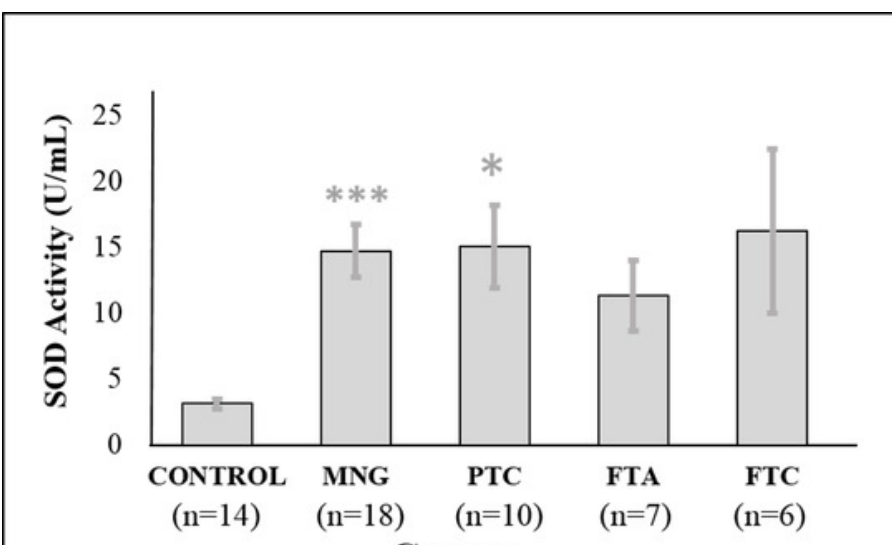

Groups

(a)

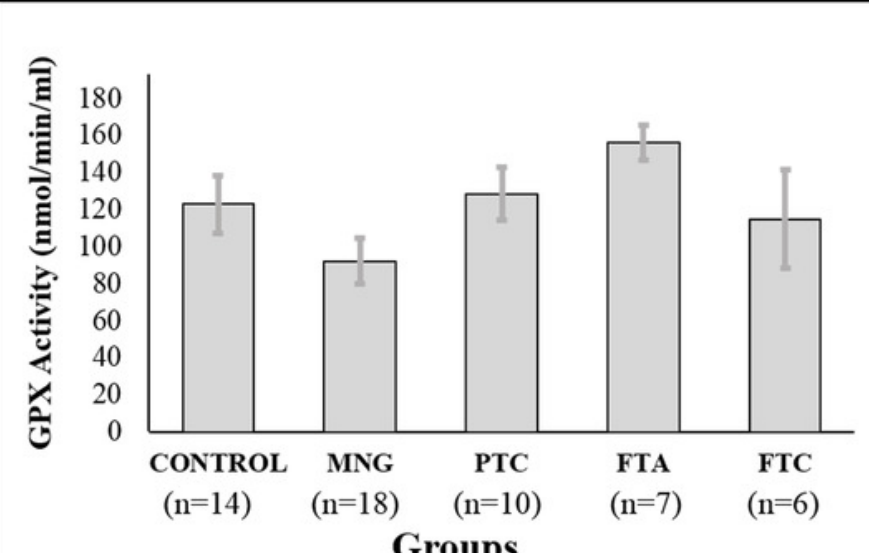

Groups

(c)

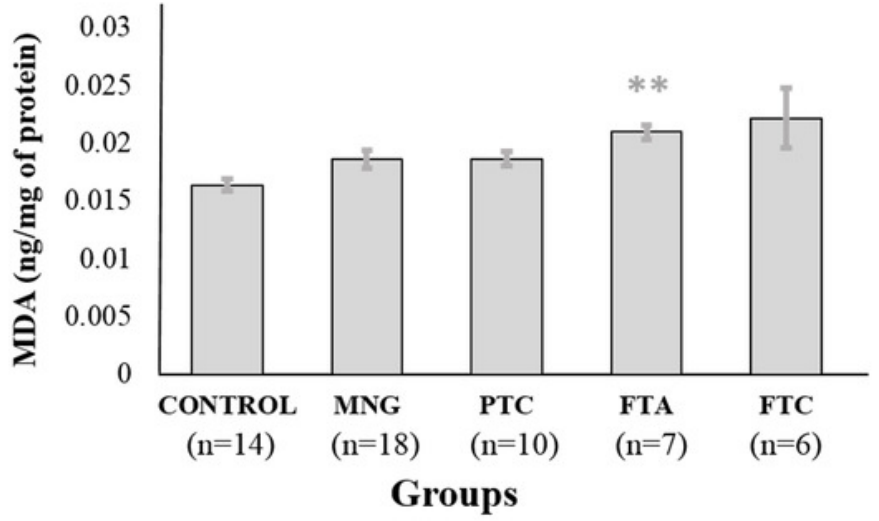

(e)

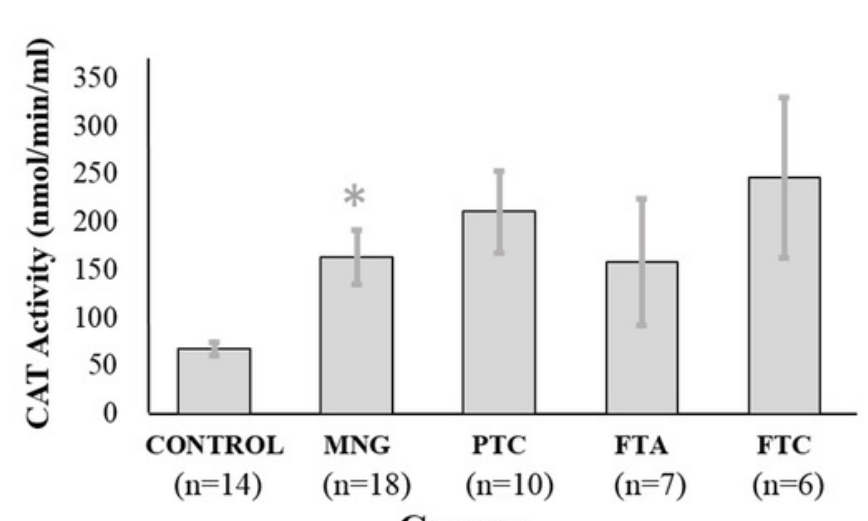

(b)

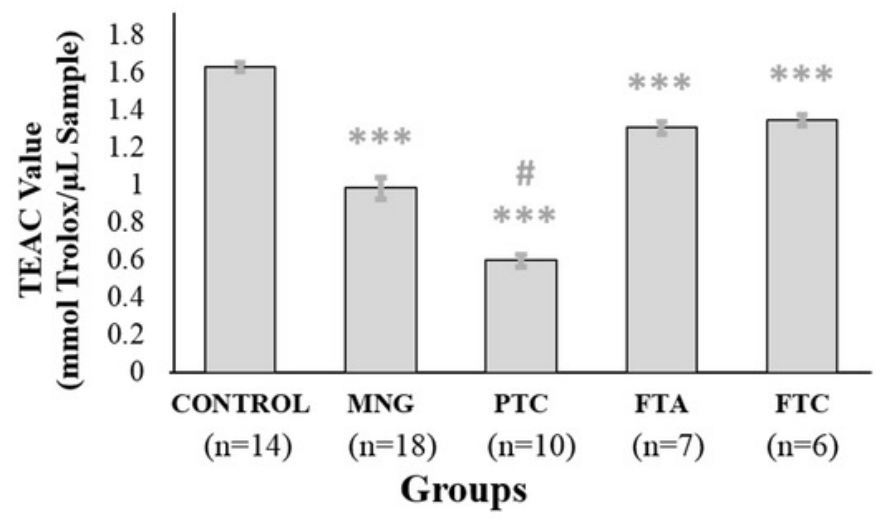

(d)

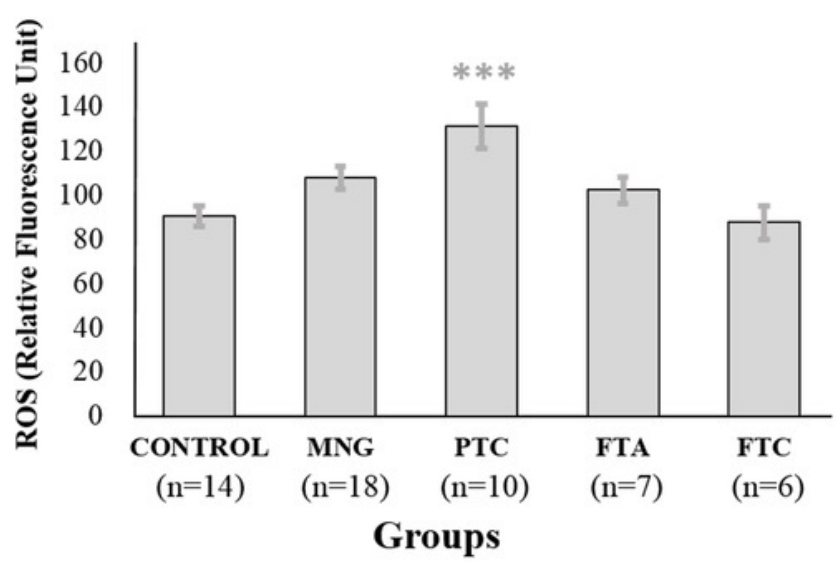

(f) 


\section{Figure 2}

\section{Antioxidant analysis in red blood cells samples of thyroid patients.}

\# indicates significant difference $(p<0.001)$ between the diseased groups of benign and malignant thyroid disorders (MNG vs PTC, FTA vs FTC).

* indicates significant difference $(p<0.05$ and $>0.01)$ between control and the diseased groups.

** indicates significant difference $(p<0.01$ and $>0.001)$ between control and the diseased groups.

*** indicates significant difference $(p<0.001$ ) between control and the diseased groups.

*Note: Auto Gamma Correction was used for the image. This only affects the reviewing manuscript. See original source image if needed for review. 


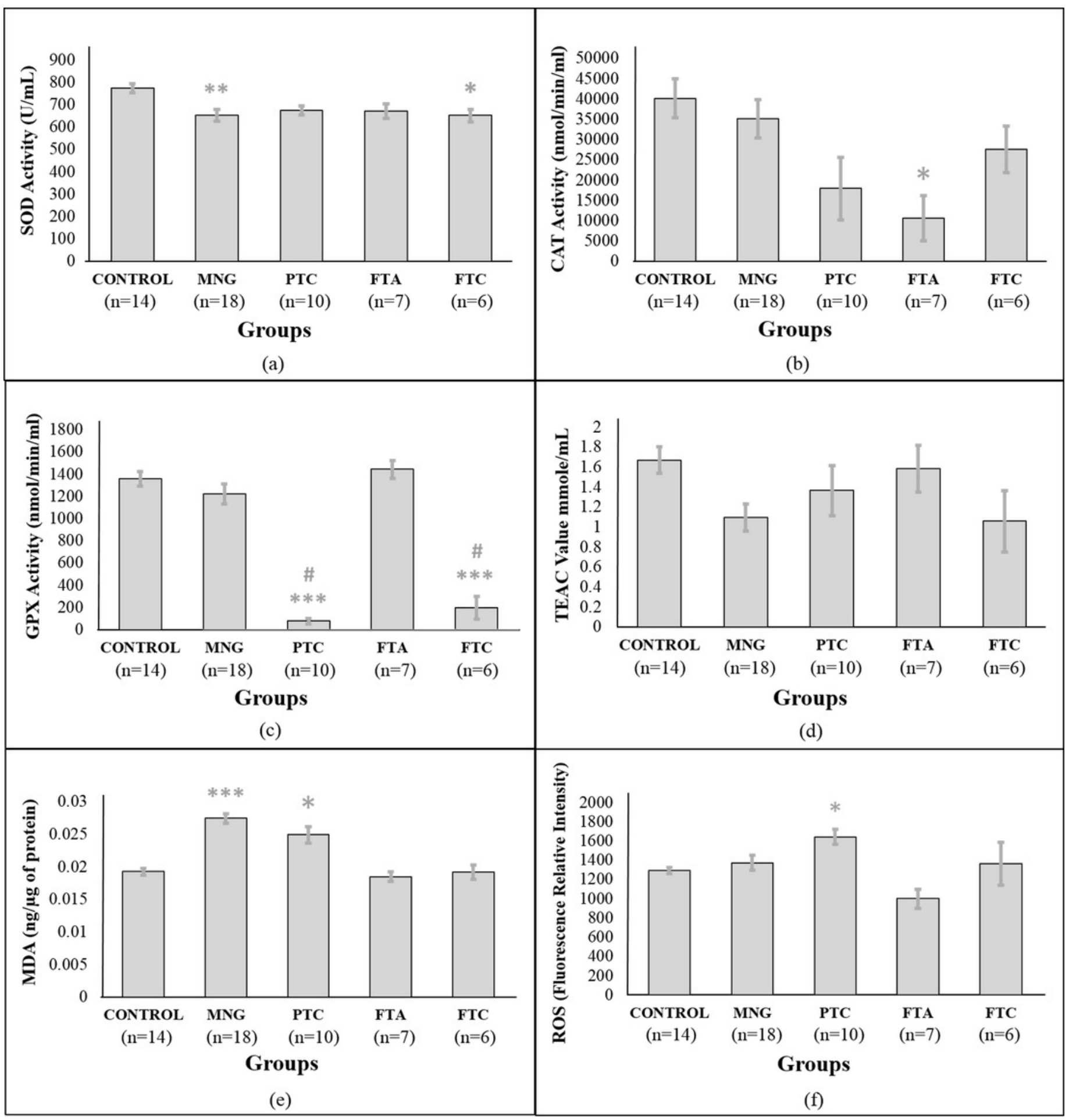


Figure 3

Venn diagrams of SNPs distribution among patients of MNG (M1-M9), PTC (P1-P9), and FTC (F1-F5).

Individual patients in each group; MNG (M1-M9), PTC (P1-P9), and FTC (F1-F5).

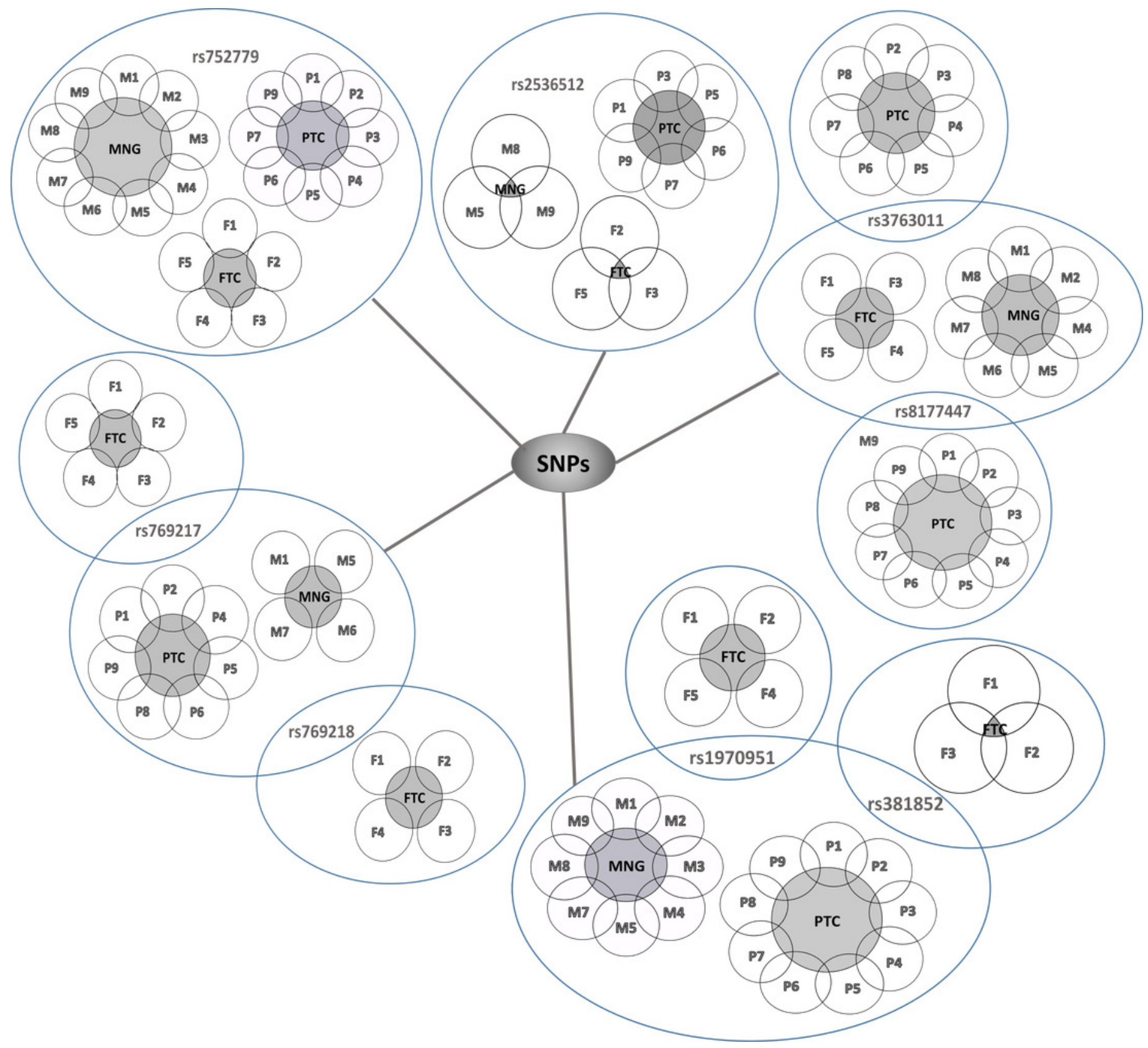




\section{Figure 4}

Allelic frequencies distribution of the highlighted eight SNPs in SOD, GPX, and CAT genes in our studied populations with comparison to the healthy individuals of South Asian (SAS) and East Asian (EAS).

The data of SAS and EAS populations were obtained from 1000 Genomes Project Phase 3 allele frequencies (Ensembl.org) 


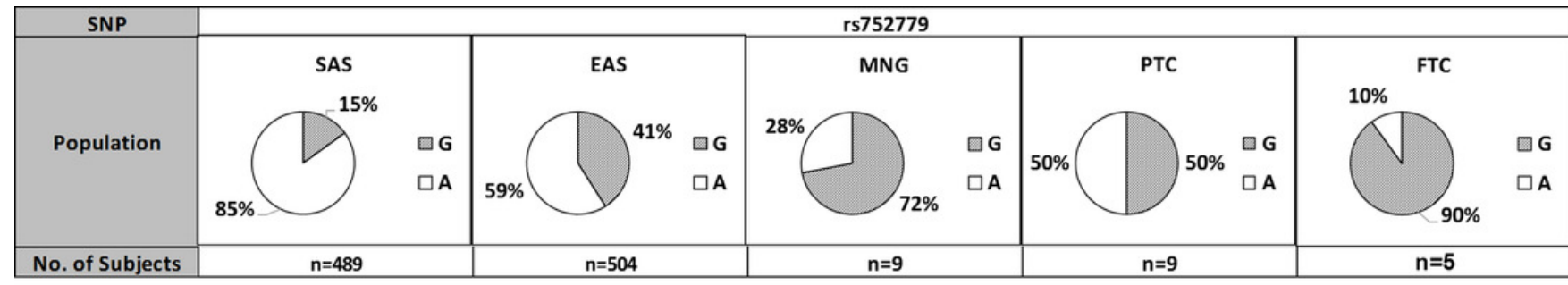

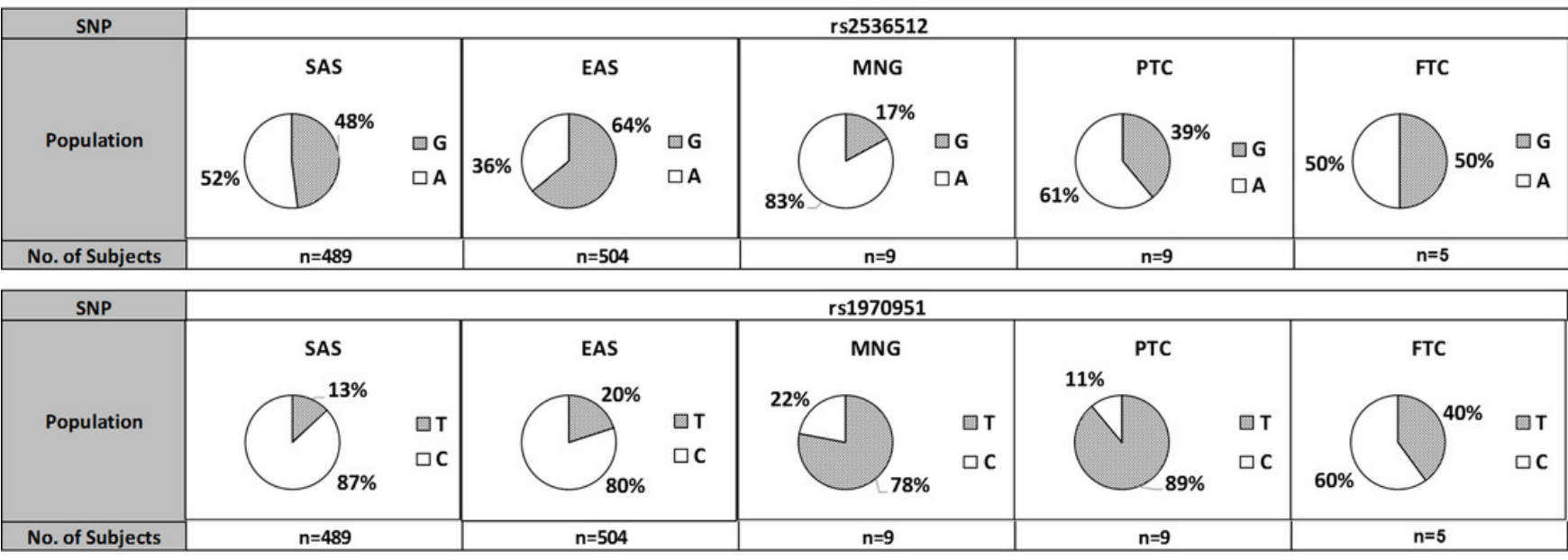

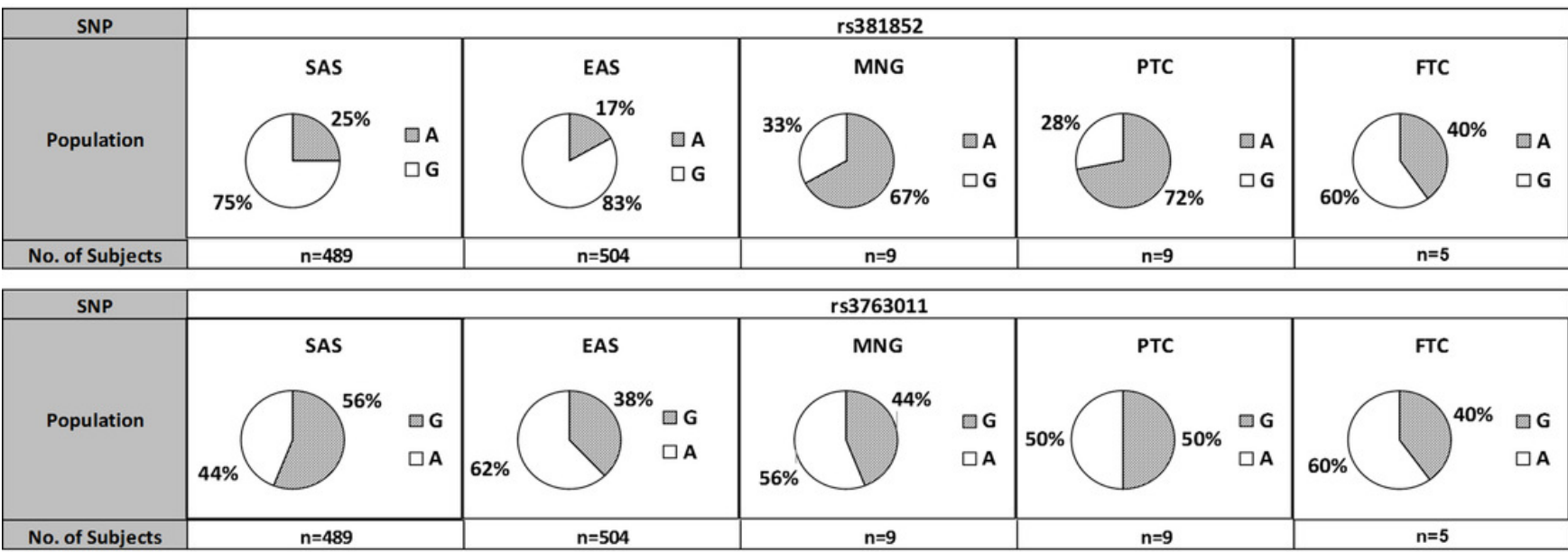

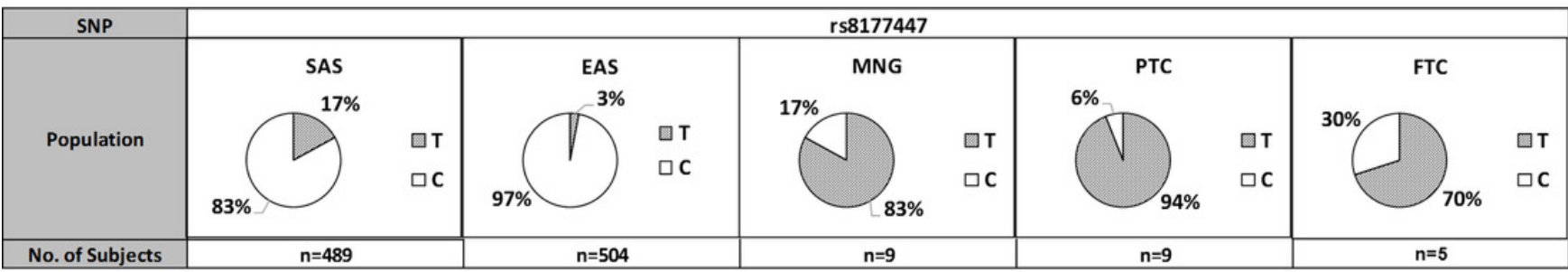

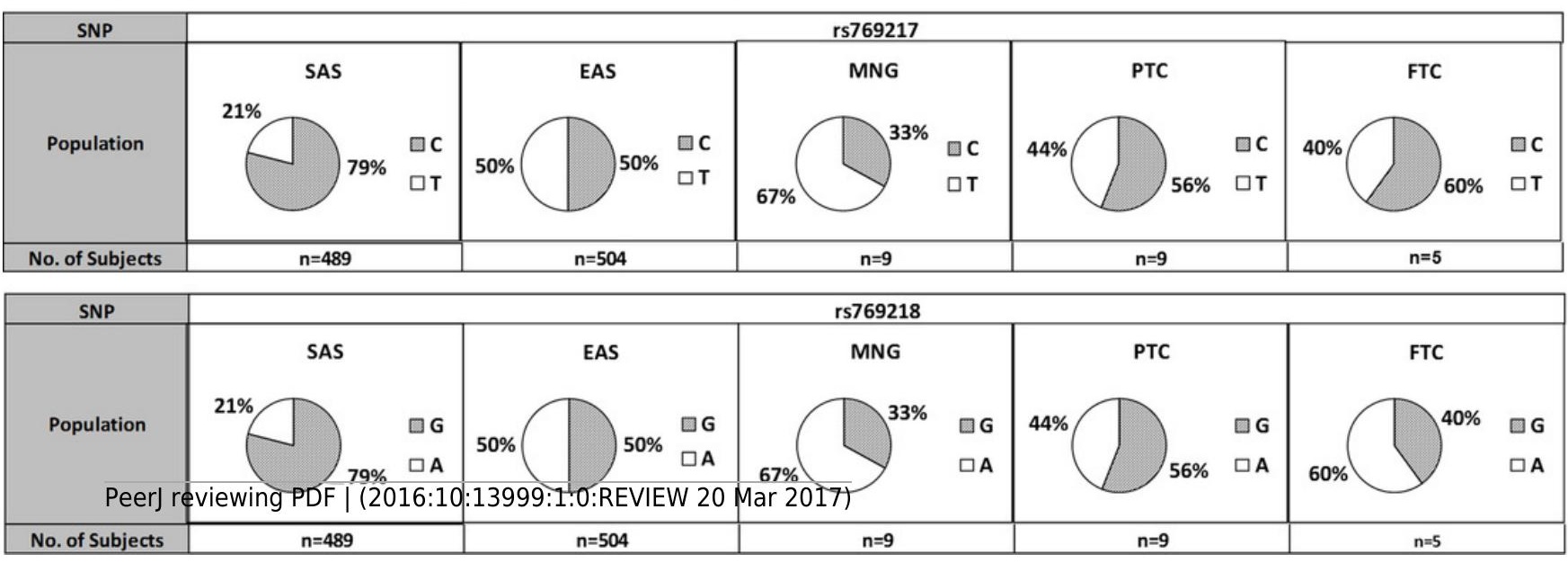


Figure 5

Associations between antioxidant enzyme activities and the total number of SNPs present in MNG and PTC groups.

Data are presented as means \pm SEM. Spearman's correlation coefficient test were expressed as $r$ for the total number of SNPs in each patients' group, where applies.

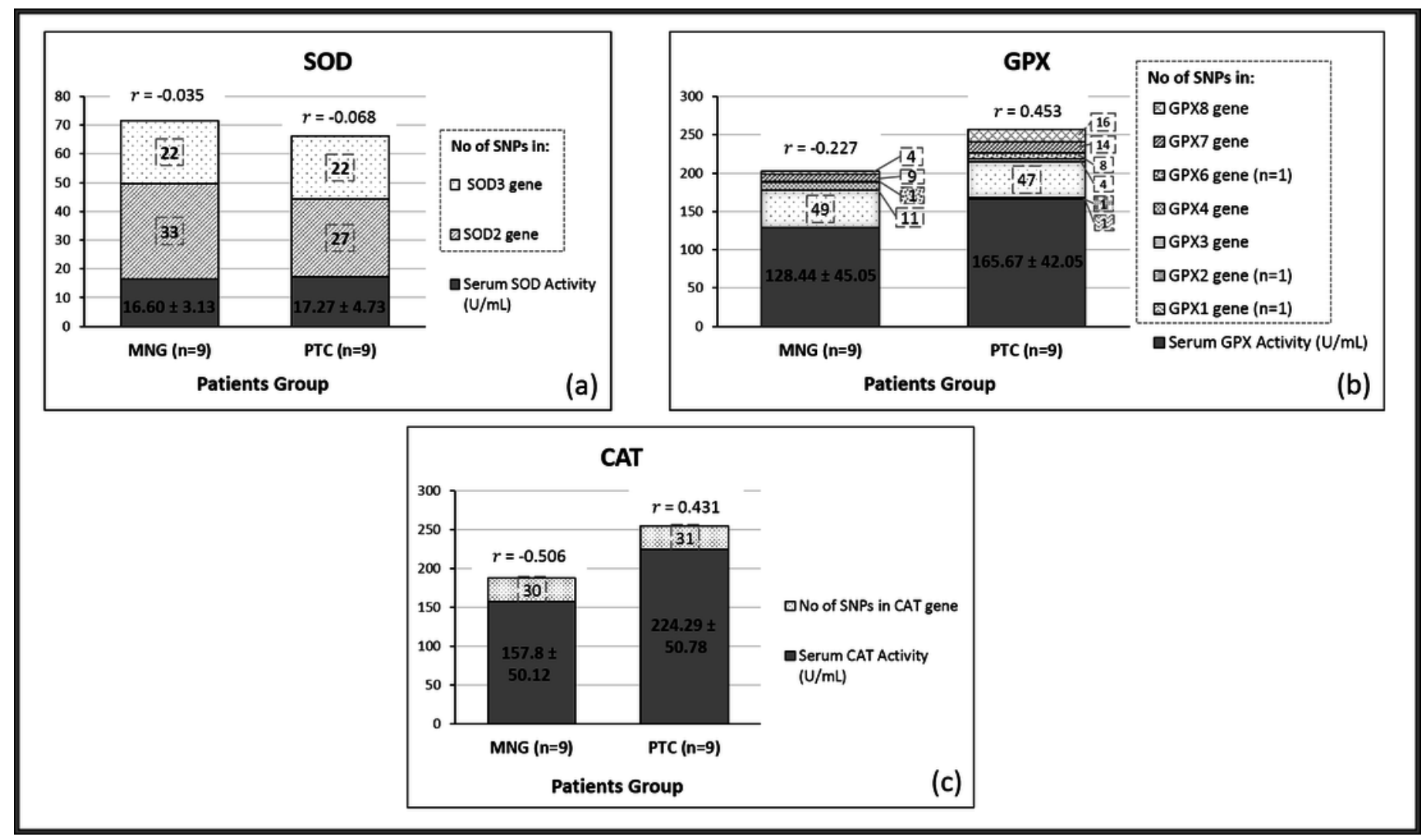




\section{Table $\mathbf{1}$ (on next page)}

Demographic and clinical characteristics of patients with their thyroid function test (TFT) results. 
1 Table 1 Demographic and clinical characteristics of patients with their thyroid function test (TFT) 2 results.

\begin{tabular}{|c|c|c|c|c|c|}
\hline & $\begin{array}{c}\text { CONTROL } \\
(\mathrm{n}=14)\end{array}$ & $\begin{array}{l}\text { MNG } \\
(\mathrm{n}=18)\end{array}$ & $\begin{array}{l}\text { FTA } \\
(\mathrm{n}=7)\end{array}$ & $\begin{array}{c}\text { PTC } \\
(\mathrm{n}=10)\end{array}$ & $\begin{array}{l}\text { FTC } \\
(\mathrm{n}=6)\end{array}$ \\
\hline Age (years) & $\begin{array}{c}32.5 \\
(29-66)\end{array}$ & $\begin{array}{c}53.5 \\
(35-71)\end{array}$ & $\begin{array}{c}34 \\
(14-72)\end{array}$ & $\begin{array}{c}49.5 \\
(22-76)\end{array}$ & $\begin{array}{c}57.5 \\
(35-80)\end{array}$ \\
\hline Gender & $\mathrm{F}: 11 \quad \mathrm{M}: 3$ & $\mathrm{~F}: 16 \quad \mathrm{M}: 2$ & F: 6 M: 1 & F: $5 \quad$ M: 5 & $\mathrm{~F}: 6 \quad \mathrm{M}: 0$ \\
\hline TSH (mU/L) & $\begin{array}{c}1.24 \\
(0.43-3.1)\end{array}$ & $\begin{array}{c}1.02 \\
(0.17-5.35)\end{array}$ & $\begin{array}{c}1.98 \\
(0.88-2.74)\end{array}$ & $\begin{array}{c}1.73 \\
(0.41-4.63)\end{array}$ & $\begin{array}{c}1.13 \\
(0.01-2.51)\end{array}$ \\
\hline fT4 (pmol/L) & $\begin{array}{c}16.3 \\
(13.6-21.5)\end{array}$ & $\begin{array}{c}16.1 \\
(12.0-20.2)\end{array}$ & $\begin{array}{c}17.9 \\
(14.2-19.4)\end{array}$ & $\begin{array}{c}16.7 \\
(13.7-19.2)\end{array}$ & $\begin{array}{c}16.05 \\
(12.4-44.5)\end{array}$ \\
\hline
\end{tabular}

3 Data are presented as median. Patient groups; MNG (multinodular goitre), FTA (follicular thyroid 4 adenoma), PTC (papillary thyroid cancer), and FTC (follicular thyroid cancer). Gender; Female 5 (F), Male (M). TSH, thyroid-stimulating hormone (normal reference range: 0.55-4.78 mU/L); fT4, 6 free thyroxine (normal reference range: $11.5-22.7 \mathrm{pmol} / \mathrm{L}$ ). 7 


\section{Table 2 (on next page)}

List of genes and SNP primers of TaqMan ${ }^{\circledR}$ SNP Genotyping Assays.

* shows a reporter dye for the specific alleles underlined and highlighted in blue. Each assay mix concentration is $40 \mathrm{X}$ in $188 \mu \mathrm{L}$ per tube. The amplicon size is NA. 
1 Table 2 List of genes and SNP primers of TaqMan® SNP Genotyping Assays

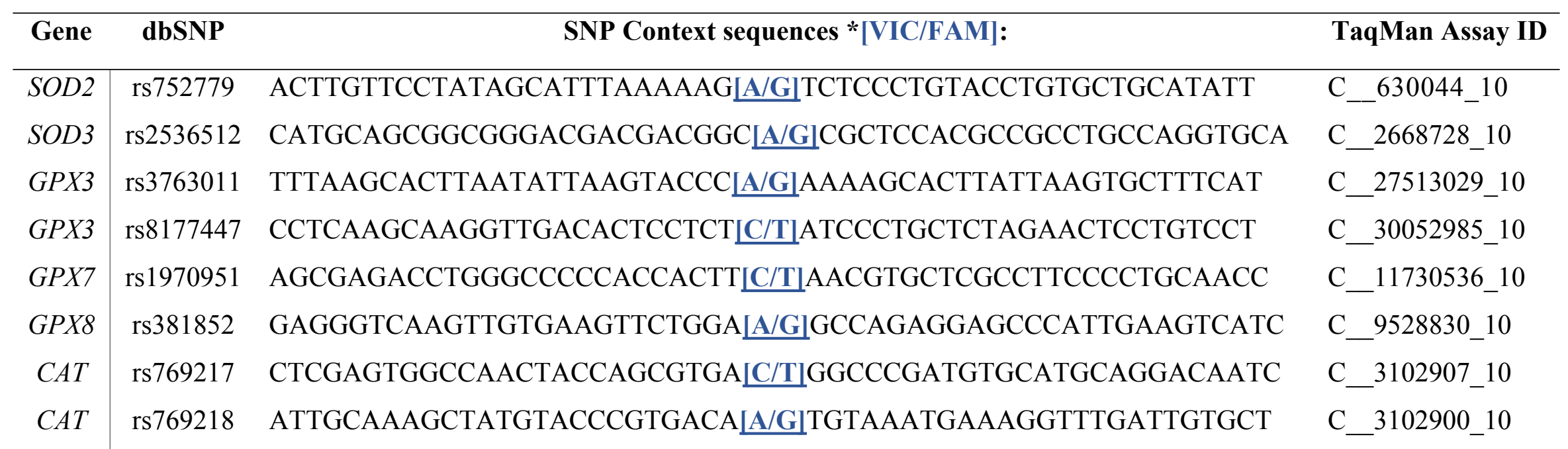

2 Note: * shows a reporter dye for the specific alleles underlined and highlighted in blue. Each assay mix concentration is $40 \mathrm{X}$ in 188

$3 \mu \mathrm{L}$ per tube. The amplicon size is NA. 


\section{Table 3(on next page)}

Characteristics and localisations of SNPs in SOD2, SOD3, GPX1, GPX2, GPX3, GPX4, GPX6, GPX7, GPX8, and CAT genes in patients with MNG and PTC.

A58T: Alanine58Threonine; E89G: Glutamic acid89Glycine; L13L: Leucine13Leucine; P12P:

Proline12Proline; L193L: Leucine193Leucine; V122V: Valine122Valine; F79F:

Phenylalanine79Phenylalanine; K182R: Lysine182Arginine; D389D: Aspartic acid389Aspartic acid; L419L: Leucine419Leucine. 
1 Table 3 Characteristics and localisations of SNPs in SOD2, SOD3, GPX1, GPX2, GPX3, GPX4, $2 G P X 6, G P X 7, G P X 8$, and $C A T$ genes in patients with MNG and PTC.

\begin{tabular}{|c|c|c|c|c|}
\hline Gene & dbSNP & Location & Types of Variants & $\begin{array}{l}\text { Base; Amino } \\
\text { acid change }\end{array}$ \\
\hline SOD2 & \begin{tabular}{|l|} 
rs44880 \\
\end{tabular} & Exon 2 & Missense & $\mathrm{A} / \mathrm{G} ; \mathrm{V} 16 \mathrm{~A}$ \\
\hline Ch6 & rs752779 & Intergenic & - & $\mathrm{G} / \mathrm{A}$; - \\
\hline \multirow[t]{4}{*}{$q 25.3$} & rs2758332 & Intron 3 & - & $\mathrm{C} / \mathrm{A} ;-$ \\
\hline & rs2855116 & Intron 3 & - & $\mathrm{A} / \mathrm{C}$ \\
\hline & rs2070994 & Intron 3 & - & $\mathrm{A} / \mathrm{T} ;-$ \\
\hline & rs2842960 & Intron 2 & - & $\mathrm{C} / \mathrm{T} ;-$ \\
\hline SOD3 & rs8192291 & Exon 2 & Synonymous & $\mathrm{C} / \mathrm{T} ; \mathrm{L} 71 \mathrm{~L}$ \\
\hline Ch4 & rs1799895 & Exon 2 & Missense & $\mathrm{C} / \mathrm{G} ; \mathrm{R} 231 \mathrm{G}$ \\
\hline \multirow[t]{3}{*}{ p15.2 } & rs2695232 & UTR3' & - & $\mathrm{C} / \mathrm{T} ;-$ \\
\hline & rs2855262 & UTR3' & - & $\mathrm{T} / \mathrm{C} ;-$ \\
\hline & rs2536512 & Exon 2 & Missense & $\mathrm{G} / \mathrm{A} ; \mathrm{A} 58 \mathrm{~T}$ \\
\hline $\begin{array}{l}\text { GPX1 } \\
C h 3 \\
p 21.3\end{array}$ & rs368623389 & Exon 1 & Missense & $\mathrm{T} / \mathrm{C} ; \mathrm{E} 89 \mathrm{G}$ \\
\hline $\begin{array}{l}G P X 2 \\
C h 14 \\
q 23.3\end{array}$ & rs17881414 & Intron 1 & - & $\mathrm{T} / \mathrm{C} ;-$ \\
\hline$G P X 3$ & rs 11548 & UTR3' & - & $\mathrm{C} / \mathrm{T} ;-$ \\
\hline Ch5 & rs2070593 & UTR3' & - & $\mathrm{G} / \mathrm{A} ;-$ \\
\hline \multirow[t]{7}{*}{$q 33.1$} & rs2277940 & UTR3' & - & $\mathrm{T} / \mathrm{C} ;-$ \\
\hline & rs8177413 & Exon 1 & Synonymous & $\mathrm{G} / \mathrm{C} ; \mathrm{L} 13 \mathrm{~L}$ \\
\hline & rs2230303 & UTR3' & - & $\mathrm{T} / \mathrm{G} ;-$ \\
\hline & rs8177448 & UTR3' & - & $\mathrm{G} / \mathrm{A} ;-$ \\
\hline & rs8177412 & UTR5 & - & $\mathrm{T} / \mathrm{C} ;-$ \\
\hline & rs3763012 & Intron 1 & - & $\mathrm{G} / \mathrm{A} ;-$ \\
\hline & rs3763011 & Intron 1 & - & $\mathrm{G} / \mathrm{A} ;-$ \\
\hline
\end{tabular}




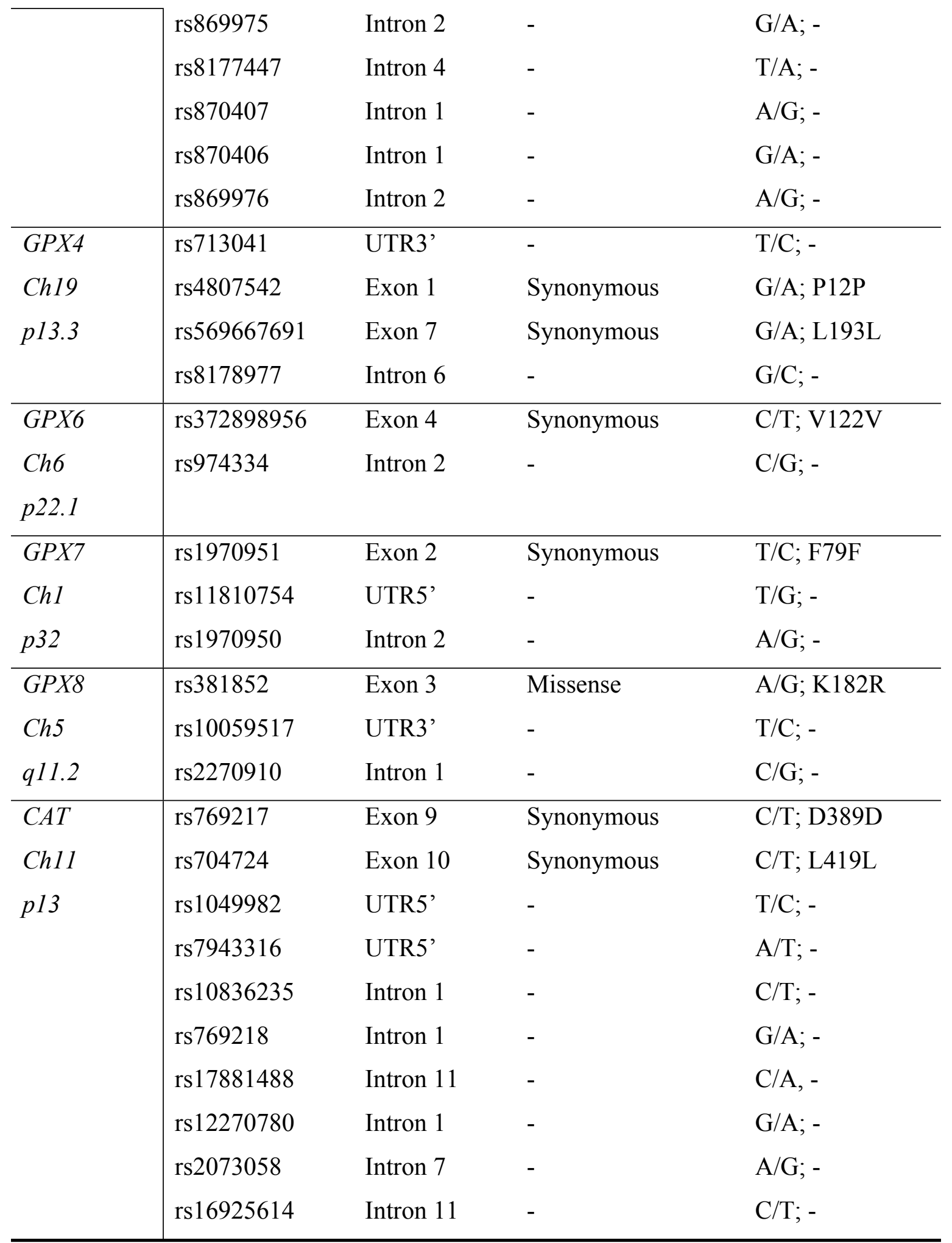

Note: A58T: Alanine58Threonine; E89G: Glutamic acid89Glycine; L13L: Leucine13Leucine; P12P: Proline12Proline; L193L: Leucine193Leucine; V122V: Valine122Valine; F79F: Phenylalanine79Phenylalanine; K182R: Lysine182Arginine; 
D389D: Aspartic acid389Aspartic acid; L419L: Leucine419Leucine.

3 


\section{Table 4 (on next page)}

Genotype and allele frequencies of the eight SNPs in MNG, PTC, and FTC patients. 
Table 4 Genotype and allele frequencies of the eight SNPs in MNG, PTC, and FTC patients.

\begin{tabular}{|c|c|c|c|c|c|c|c|c|c|c|c|c|c|c|c|}
\hline \multirow[t]{2}{*}{ SNPs } & \multirow[t]{2}{*}{ Genotype } & \multicolumn{5}{|c|}{ No of Patients $(\%)^{a}$} & \multirow[t]{2}{*}{$P$ value } & \multirow[t]{2}{*}{ Allele } & \multicolumn{6}{|c|}{ Total Haplotypes (\%) } & \multirow[t]{2}{*}{ P value } \\
\hline & & $\mathrm{MNG}(\mathrm{n}=9)$ & \multicolumn{2}{|c|}{ PTC $(n=9)$} & \multicolumn{2}{|c|}{ FTC $(n=5)$} & & & \multicolumn{2}{|c|}{$\mathrm{MNG}$} & \multicolumn{2}{|c|}{ PTC } & \multicolumn{2}{|c|}{ FTC } & \\
\hline \multirow{3}{*}{ rs752779 } & $\overline{\mathrm{GG}}$ & $4 \quad(44)$ & 1 & $(11)$ & 4 & $(80)$ & $* 0.03$ & $\bar{G}$ & 13 & $(72)$ & 9 & $(50)$ & 9 & $(90)$ & 0.08 \\
\hline & GA & $5 \quad(56)$ & 7 & (78) & 1 & $(20)$ & & A & 5 & (28) & 9 & $(50)$ & 1 & $(10)$ & \\
\hline & AA & $0 \quad(0)$ & 1 & (11) & 0 & $(0)$ & & & & & & & & & \\
\hline \multirow{3}{*}{ rs 2536512} & GG & $0 \quad(0)$ & 1 & (11) & 2 & $(40)$ & 0.22 & G & 3 & (17) & 7 & (39) & 5 & $(50)$ & 0.14 \\
\hline & GA & $3 \quad(33)$ & 5 & (56) & 1 & (20) & & A & 15 & (83) & 11 & (61) & 5 & $(50)$ & \\
\hline & AA & $6 \quad(67)$ & 3 & (33) & 2 & (40) & & & & & & & & & \\
\hline \multirow{3}{*}{ rs1970951 } & TT & $6 \quad(67)$ & 7 & (78) & 0 & $(0)$ & $* 0.05$ & $\mathrm{~T}$ & 14 & (78) & 16 & (89) & 4 & (40) & $* 0.03$ \\
\hline & $\mathrm{TC}$ & $2 \quad(22)$ & 2 & (22) & 4 & (80) & & $\mathrm{C}$ & 4 & (22) & 2 & (11) & 6 & (60) & \\
\hline & $\mathrm{CC}$ & $1 \quad(11)$ & 0 & (0) & 1 & (20) & & & & & & & & & \\
\hline \multirow{3}{*}{ rs381852 } & $\mathrm{AA}$ & $4 \quad(45)$ & 5 & $(56)$ & 1 & (20) & 0.32 & $\mathrm{~A}$ & 12 & (67) & 13 & (72) & 4 & (40) & 0.25 \\
\hline & $\mathrm{AG}$ & $4 \quad(45)$ & 3 & (33) & 2 & (40) & & $\mathrm{G}$ & 6 & (33) & 5 & (28) & 6 & (60) & \\
\hline & GG & $1 \quad(10)$ & 1 & (11) & 2 & (40) & & & & & & & & & \\
\hline \multirow{3}{*}{ rs3763011 } & GG & $1 \quad(11)$ & 2 & (22) & 0 & $(0)$ & 0.91 & $\mathrm{G}$ & 8 & (44) & 9 & $(50)$ & 4 & (40) & 0.93 \\
\hline & GA & $6 \quad(67)$ & 5 & (56) & 4 & $(80)$ & & A & 10 & (56) & 9 & (50) & 6 & (60) & \\
\hline & AA & $2 \quad(22)$ & 2 & (22) & 1 & (20) & & & & & & & & & \\
\hline \multirow{3}{*}{ rs8177447 } & TT & $7 \quad(78)$ & 8 & (89) & 3 & (60) & 0.55 & $\mathrm{~T}$ & 15 & (83) & 17 & (94) & 7 & $(70)$ & 0.25 \\
\hline & $\mathrm{TC}$ & $1 \quad(11)$ & 1 & (11) & 1 & (20) & & $\mathrm{C}$ & 3 & (17) & 1 & (6) & 3 & (30) & \\
\hline & $\mathrm{CC}$ & $1 \quad(11)$ & 0 & (0) & 1 & (20) & & & & & & & & & \\
\hline \multirow{3}{*}{ rs769217 } & $\mathrm{CC}$ & 2 (22) & 3 & (34) & 1 & (20) & 0.42 & $\mathrm{C}$ & 6 & (33) & 10 & (56) & 6 & $(60)$ & 0.36 \\
\hline & $\mathrm{CT}$ & $2 \quad(22)$ & 4 & (44) & 4 & $(80)$ & & $\mathrm{T}$ & 12 & (67) & 8 & (44) & 4 & (40) & \\
\hline & $\mathrm{TT}$ & $5 \quad(56)$ & 2 & (22) & 0 & (0) & & & & & & & & & \\
\hline \multirow{3}{*}{ rs769218 } & GG & $2(22)$ & 3 & (34) & 0 & (0) & 0.54 & $\mathrm{G}$ & 6 & (33) & 10 & (56) & 4 & (40) & 0.48 \\
\hline & GA & $2 \quad(22)$ & 4 & (44) & 4 & $(80)$ & & A & 12 & (67) & 8 & (44) & 6 & (60) & \\
\hline & AA & $5 \quad(56)$ & 2 & (22) & 1 & (20) & & & & & & & & & \\
\hline
\end{tabular}

$2{ }^{\mathrm{a}}$ Genotype frequencies and ${ }^{\mathrm{b}}$ allele frequencies were determined by Fisher's exact test analysis and $* \mathrm{p}<0.05$ was considered

3 statistically significant between the 3 groups. All genotypes in MNG, PTC, and FTC populations were in associations with HW ( $p>$

4 0.05). 